\title{
Valuation of Shares and Equity Financing in an Economy with Frictions but no Leverage: the Value of Retained Earnings ${ }^{1}$
}

\author{
Tom Copeland* and Andrew Lyasoff ${ }^{* *}$ \\ * Monitor Group and MIT and ** Boston University
}

\begin{abstract}
We develop a pricing method and derive an optimal equity financing strategy for a unlevered firm with constant production cost, constant production rate, stochastic output price and an option to expand in a non-competitive economy. The effects of taxes, transaction costs and non-liquidity on the share values and the optimal equity financing policy is studied. Shares of common stock in the firm are treated as contingent claims on two underlying instruments: the firm's retained earnings and the stochastic output price. The paper presents a numerical procedure for computing both the share value and the marginal rate of substitution of retained earnings (MRSRI). It is shown that in the absence of taxes and transaction costs, the MRSRI for a perfectly liquid firm is reduced to the constant 1 - this is a restatement of the classical Modigliani-Miller proposition in the context of dynamic programming. The study of the MRSRI in an economy with frictions may be viewed as an extension of the Modigliani-Miller theory.
\end{abstract}

The main ingredient in the quantitative capital structure theory pioneered by Brenan and Schwartz [3] and Leland [9] is the price process associated with the asset value of the firm, i.e., the value that remains invariant under changes in the financial structure of the firm. It is common to assume that the asset value follows some exogenously given diffusion process - for example, the theory developed in [9] is based on the assumption that the asset value follows a diffusion process with constant volatility. The notion of value which is invariant under changes in the financial structure has been a central tenet in the capital structure theory since its inception in the works of Modigliani and Miller [17] and [18]. It is well known, however, that in general the classical Modigliani-Miller proposition does not hold in an economy with frictions by «frictions» we mean lack of liquidity, and/ or presence of transaction costs, and/ or presence of taxes. Indeed, if raising investment capital by issuing new equity or by taking new debt costs money, or simply is not available as a financial instrument, investors would not be equally attracted to two different firms that have substantially different levels of retained earnings but are otherwise identical. In addition, if shares of equity in the firm are not publicly traded, one can no longer perceive the asset value as being determined exogenously by the market.

Most recent studies - see [8], for example — indicate that the mathematics of a frictionless economy differs substantially from the mathematics of an economy with frictions. The present work grew out of the desire to find a quantitative answer to the question: By how much does the Modigliani-Miller proposition fail in an economy with frictions? One can rephrase this question as: By how much does the addition of $\varepsilon$ units of money to the firm's cash reserve increase its value, if the firm has no access to equity financing or debt financing, or, if the trade of equity in the firm involves transaction costs, or, if the dividends paid out to the shareholders are subject to taxes? Clearly, this last question cannot be answered without specific assumptions about the firm's investment opportunities and about the rate at which the firm gener: ates profits at the moment. Thus, our study will be confined to a very concrete model in which the firm owns one production facility and also owns an option to expand. We will consider only the case of an economy which does not allow debt financing. Liquid: 
ity will be understood simply as the firm's ability to issue - and sell by various meth: ods - new equity in the firm. Of course, if one is to assume that the firm is not traded on a stock exchange, one must somehow derive the associated price process, instead of assuming that the price process is determined exogenously by the market. We will derive the value of the illiquid firm in terms of contingent claims analysis by treating the firm as a derivative claim on two underlying assets: the price, $X_{t}$, of the firm's output, and the level, $Y_{t}$, of retained earnings that remain in the firm at time $t \geqslant 0$. To understand the intuition behind this approach, notice that if one knows the earning rate and knows how much additional capital must be accumulated before the firm can exercise the option to expand, then - on principle, at least - one should be able to determine the time left until the investment opportunity can be exercised, so that the firm can indeed be treated as an option with a given - possibly stochastic - time to expiry. Consequently, the value of the firm can be expressed as $V\left(X_{t}, Y_{t}\right), t \geqslant 0$, in terms of the valuation map ( $\mathrm{x}, \mathrm{y}) \longrightarrow \mathrm{V}$ ( $\mathrm{x}, \mathrm{y})$ that satisfies a special two-dimensional analog of the classical Black-Scholes equation - see [1], [14], [15]. Once the function $\mathrm{V}(\cdot, \cdot)$ is computed from the appropriate boundary conditions, the answer to the above question becomes completely straightforward: increasing the firm's cash reserve by $\varepsilon$ units of money increases its value by the amount $\mathrm{V}\left(\mathrm{X}_{\mathrm{t}}, \mathrm{Y}_{\mathrm{t}}+\varepsilon\right)-\mathrm{V}\left(\mathrm{X}_{\mathrm{t}}, \mathrm{Y}_{\mathrm{t}}\right)$ and, in general, the partial derivative $\mathrm{V}^{(0,1)}\left(\mathrm{X}_{\mathrm{t}}, \mathrm{Y}_{\mathrm{t}}\right)$ gives the rate at which the infusion of cash in the firm improves its value - this quantity is the same as the rate at which the firm's owner is willing to substitute personal cash for cash in the firm, as explained below.

The value of the liquid firm, too, will be derived in terms of contingent claims analysis. In this context, liquidity can be understood as the firm's ability to exercise the option to expand at any moment $t \geqslant 0$ : assuming that the expansion project costs $I$ units of money to install and the level of retained earnings is $\mathrm{Y}_{\mathrm{t}}<I$, the owner of the firm must decide whether to take no action and wait until the retained earnings increase by $\Delta$ units of money before the next decision can be made, or, immediately issue equity worth $I-\mathrm{Y}_{\mathrm{t}}$ units of money and acquire a percentage of ownership in an enterprise worth $\mathrm{V}\left(\mathrm{X}_{\mathrm{t}}, \mathcal{I}\right)$ units of money. It turns out that this dynamic approach is entirely consistent with the Modigliani-Miller theory: in the absence of taxes and transaction costs, the value function has the property $\mathrm{V}^{(0,1)}\left(\mathrm{X}_{\mathrm{t}}, \mathrm{Y}_{\mathrm{t}}\right) \equiv 1$ for any $\mathrm{t} \geqslant 0$. Unfortunately, even without taxes and transaction costs, the associated price process $\mathrm{V}\left(\mathrm{X}_{\mathrm{t}}, \mathrm{Y}_{\mathrm{t}}\right), \mathrm{t} \geqslant 0$, does not exhibit constant volatility, as a result of which the closedform results for the value of risky debt and the optimal capital structure obtained in [9] and [10] cannot be used in our setting. On the other hand, the price process derived for a liquid firm which is free of taxes and transaction costs is consistent with the well known models studied by Dixit and Pindyck in [4]. Of course, if the assump: tion for complete liquidity and the lack of any other frictions is dropped, one can no longer view the firm's debt as a claim on the firm's price alone - for example, if raising cash by way of equity financing is not costless, a higher level of retained earnings would make bankruptcy less likely. Consequently, while this goes beyond the scope of the present paper, the firm's debt, too, may be treated as a claim on the output price and the firm's retained earnings.

The numerical procedure used to calculate the valuation map $\mathrm{V}(\cdot, \cdot)$ is based on the method developed in [13] and bears some similarity to the binomial method the main difference is that instead of computing averages of values attached to the nodes on the tree, in this procedure one computes expected values of future payoffs in 
the way prescribed by the Feynman-Kac formula, where the payoff functions are con: structed by way of polynomial interpolation from a discrete set of values. On principle, the same numerical technique can be used for pricing general claims on the output price and the firm's retained earnings, including, as explained above, the price of debt.

\section{§1. The Firm with an Option to Expand}

The main object of study in the present paper is a firm without a competitor that owns one factory and also owns the monopoly right - yet to be exercised - to build a sec: ond factory identical to the existing one. We will refer to this financial entity as «the firm with an option to expand». It will be assumed that the option to build a second factory - and therefore to double the current output rate - represents the only oppor: tunity for expansion in the future, i.e., once the second factory is installed, the firm's output rate will remain forever fixed at twice the output rate of a single factory. The term «factory» will always refer to a production facility with a fixed output rate of 1 unit of output per unit of time, fixed production cost of $c$ units of money per unit of time and the ability to suspend production at no cost when the output price, $\mathrm{X}_{\mathrm{t}}$, falls below the production cost, $c$. It will be assumed that the output is produced continu: ously and that the production cost is incurred continuously, too; for example, if the unit of time is one year, then $\frac{1}{12}$ units of output are produced every month at the cost of $\frac{c}{12}$ units of money, $\frac{1}{52}$ units of output are produced every week at the cost of $\frac{c}{52}$ units of money, and so on. The price of 1 unit of output, measured in the same units of money, is assumed to follow the stochastic process $X_{t}, t \geqslant 0$, governed by the equation

$$
d \mathrm{X}_{\mathrm{t}}=\sigma \mathrm{X}_{\mathrm{t}} d \beta_{\mathrm{t}}+\alpha \mathrm{X}_{\mathrm{t}} d \mathrm{t}, \mathrm{t} \geqslant 0,
$$

in which $\sigma>0$ and $\alpha>0$ are given parameters and $\beta_{\mathrm{t}}, \mathrm{t} \geqslant 0$, is some standard Brown: ian motion process. Notice that the stochastic equation (1.1) determines the price process $X_{t}, t \geqslant 0$, only if the initial value $X_{0}$ is specified. If the choice of the initial price $\mathrm{X}_{0}=\mathrm{x} \in \mathbb{R}$ must be reflected in the notation, we will denote the price process by $X_{t}^{x}, t \geqslant 0$. Thus, at time $t \geqslant 0$ a single factory generates profit at rate $\pi\left(X_{t}\right):=$ $\operatorname{Max}\left[X_{t}-c, 0\right]$, i.e., the profit generated during any time period $\llbracket t, t+\Delta \rrbracket$, for $\Delta>0$, can be expressed as $\pi\left(\mathrm{X}_{\mathrm{t}}\right) \times \Delta+\mathrm{o}(\Delta)$, where $\mathrm{o}(\Delta)$ reads «small o of $\Delta$ ». Following [4], we will express the expected rate of growth in the output price as $\alpha=\varrho-\delta$, where $\delta>0$ denotes the convenience yield rate from the firm's output. The convenience yield can be perceived as some kind of an "intangible dividend" that the owners of the firm's output are entitled to collect. Essentially, this is a way of saying that future output from the firm must be discounted at rate $\varrho$ which is strictly larger than the expected rate of growth in the output price - as explained in [4], without this feature the value of the firm would be infinitely big.

Let $Y_{t}$ denote the level of retained earnings that remain in the firm with an option to expand at time $t \geqslant 0$. Assuming that the firm retains all of its earnings and earns interest at the - once and for all fixed - risk-free rate $r>0$ from any cash that it holds, the process $Y_{t}, t \geqslant 0$, must be governed by the equation

$$
d \mathrm{Y}_{\mathrm{t}}=\left(\pi\left(\mathrm{X}_{\mathrm{t}}\right)+\mathrm{r} \mathrm{Y}_{\mathrm{t}}\right) d \mathrm{t}, \mathrm{t} \geqslant 0 \text {. }
$$

Ownership in the firm with an option to expand will be treated as a contingent claim on two underlying assets: the output price $X_{t}, t \geqslant 0$, and the firm's retained earnings

$Y_{t}, t \geqslant 0$. This implies that at any moment $t \geqslant 0$ the present value of the firm can be expressed in the form $\mathrm{V}\left(\mathrm{X}_{\mathrm{t}}, \mathrm{Y}_{\mathrm{t}}\right)$, with the help of the valuation map 


$$
\mathbb{R}_{++} \times \mathbb{R}_{+} \ni(\mathrm{x}, \mathrm{y}) \longrightarrow \mathrm{V}(\mathrm{x}, \mathrm{y}) \in \mathbb{R}_{++},
$$

that can be computed independently from the observations $X_{t}, t \geqslant 0$, and $Y_{t}, t \geqslant 0$. Our main goal is to compute the valuation map $\mathrm{V}(\cdot, \cdot)$ by using standard contingent claims analysis and to study its behavior under various assumptions about the tax policy and the type of equity financing which is available to the firm.

It is well known - see [4], for example - that, from the point of view of contin: gent claims analysis, at any moment $t \geqslant 0$ the present value of a single factory, treated as an independent financial entity without any option to expand, can be expressed as $\mathrm{g}\left(\mathrm{X}_{\mathrm{t}}\right)$ in terms of the valuation map $\mathbb{R}_{++} \ni \mathrm{x} \longrightarrow \mathrm{g}(\mathrm{x}) \in \mathbb{R}_{++}$given by

$$
\mathrm{g}(\mathrm{X})=\left\{\begin{array}{l}
\frac{c^{1-\beta_{1}\left(\mathrm{r}+(\delta-\mathrm{r}) \beta_{2}\right)}}{\mathrm{r} \delta\left(\beta_{1}-\beta_{2}\right)} \mathrm{X}^{\beta_{1}}, \text { for } 0<\mathrm{X} \leqslant \mathrm{C} \\
\frac{c^{1-\beta_{2}}\left(\mathrm{r}+(\delta-\mathrm{r}) \beta_{1}\right)}{\mathrm{r} \delta\left(\beta_{1}-\beta_{2}\right)} \mathrm{X}^{\beta_{2}}+\frac{\mathrm{P}}{\delta}-\frac{c}{\mathrm{r}}, \text { for } \mathrm{X}>\boldsymbol{c}
\end{array},\right.
$$

where $\beta_{1}>1$ and $\beta_{2}<0$ are the two distinct roots of the fundamental quadratic equa: tion

$$
\frac{1}{2} \sigma^{2}(\beta-1) \beta+(\varrho-\delta) \beta=\varrho .
$$

Recall that (1.4) is derived in [4] under the assumption that the firm's profit is not subject to taxes. If the firm's profit is taxed at rate $\theta \in \rrbracket 0,1 \llbracket$, a single factory would generate profit only at rate $(1-\theta) \pi\left(\mathrm{X}_{\mathrm{t}}\right), \mathrm{t} \geqslant 0$, and, by using the same type of analysis - the same calculation, in fact - one can show that at time $t \geqslant 0$ the present value of the factory is given by $g_{\theta}\left(X_{t}\right):=(1-\theta) g\left(X_{t}\right)$, where $g(\cdot)$ is the valuation map defined in (1.4).

The value of the option to invest in a new factory, viewed as an independent financial instrument, also may be treated as a contingent claim on the output price. More specifically, it is shown in [4] that if all profits from the new factory are expected to be tax-free, then at time $t \geqslant 0$ the present value of the option to invest in a new factory can be expressed as $\mathrm{q}\left(\mathrm{X}_{\mathrm{t}}\right)$ in terms of the valuation map $\mathbb{R}_{++} \ni \mathrm{x} \rightarrow \mathrm{q}(\mathrm{x})$ $\in \mathbb{R}_{++}$given by

$$
q(x)=\left\{\begin{array}{l}
A x^{\beta_{1}}, \quad \text { for } 0<x \leqslant x^{*} \\
g(x)-\mathcal{I}, \text { for } \mathrm{x}>\mathrm{x}^{*} .
\end{array}\right.
$$

In the last expression the quantity $\mathcal{I}$ represents the fixed (and known) cost of building a new factory and the coefficient $\mathrm{A}$ and the price threshold $0<\mathrm{x}^{*}<\infty$ that triggers new investment - essentially, the quantity $\mathrm{x}^{*}$ prescribes the optimal investment rûle: invest immediately if $X_{t} \geqslant x^{*}$ and do nothing if $X_{t}<x^{*}-$ are both found from the system (these are the so called value-matching and smooth pasting conditions)

$$
\mathrm{A} \times\left(\mathrm{x}^{*}\right)^{\beta_{1}}=\mathrm{g}\left(\mathrm{x}^{*}\right)-\mathcal{I} \quad \& \mathrm{~A} \times \beta_{1} \times\left(\mathrm{x}^{*}\right)^{\beta_{1}-1}=\mathrm{g}^{\prime}\left(\mathrm{x}^{*}\right),
$$

treated in the domain $\mathrm{x}^{*} \in \llbracket c+\mathrm{r} \mathcal{I}, \infty \rrbracket$ and $\mathrm{A} \in \mathbb{R}_{++}$. Notice that when $\mathrm{A}$ and $\mathrm{x}^{*}$ satisfy the above conditions one has

$$
\mathrm{g}\left(\mathrm{x}^{*}\right)-\mathcal{I}=\mathrm{A} \times\left(\mathrm{x}^{*}\right)^{\beta_{1}}>0 .
$$

In particular, $\mathrm{g}(\mathrm{x})-\mathcal{I}>0$ whenever $\mathrm{x} \geqslant \mathrm{x}^{*}$. This shows that the payoff from exercising the investment opportunity is strictly positive whenever exercising happens to be optimal. As a result, the optimal exercise of the option to invest leads to the creation of new wealth. This phenomenon is well known and does not represent an arbitrage opportunity of any kind: the newly-created wealth is simply the reward for investing some time earlier (say, in terms of research and development) in the option to eventu: 
ally establish a new factory. Thus, when $X_{t} \geqslant x^{*}$ the quantity $g\left(X_{t}\right)-\mathcal{I}$ is very similar to the payoff from a call option when the underlying asset happens to be in the money. There is a subtle difference, however: when a call option is exercised, someone's gain becomes someone else's loss and no new wealth gets created, while exercising the option to invest in a new factory creates new wealth, which is no one's loss. It should be clear that unless new wealth does get created when the option to invest is exercised, in general, research and development projects would be of no value and the install: ment of new production facilities will not be creating growth in the economy. In essence, the present paper is a study - confined, of course, to the framework of a simple firm with an option to expand - of the way in which this new wealth gets distrib: uted among old and new equity holders as a result of equity trading or internal financ: ing.

1:1 (Remark) It is well known - see Ch.8 in [4], for example - that condition (1.7) does not hold in a competitive economy - say, in an economy without patent regula: tions - that has reached an equilibrium state. Indeed, under some fairly standard assumptions, it is shown in [4] that in an economy with an unlimited number of identi: cal firms that can enter the market, the output price never exceeds the critical thresh: old $\mathrm{x}^{*}$ that triggers investment and no new wealth gets created when the option to invest is exercised; in particular, in a competitive economy, the option to build a new factory is worthless, even though the value of an already existing factory is strictly positive.

Of course, when all profits from the factory that will be built in the future are expected to be taxed at rate $\theta \in \llbracket 0,1[$, the relations (1.5) and (1.6) no longer hold and the price-threshold $\mathrm{x}^{*}$ that triggers investment is higher. By using the same type of analysis, one can show that in this latter case the present value at time $t \geqslant 0$ of the option to invest in a new factory - again treated as an independent financial instru: ment - can be expressed as $\mathrm{q}_{\theta}\left(\mathrm{X}_{\mathrm{t}}\right)$ in terms of the valuation map $\mathbb{R}_{++} \ni \mathrm{x} \rightarrow \mathrm{q}_{\theta}(\mathrm{x})$ $\in \mathbb{R}_{++}$given by

$$
\mathrm{q}_{\theta}(\mathrm{x})=\left\{\begin{array}{l}
\mathrm{A}_{\theta} \mathrm{x}^{\beta_{1}}, \quad \text { for } 0<\mathrm{x} \leqslant \mathrm{x}_{\theta}^{*} \\
\mathrm{~g}_{\theta}(\mathrm{x})-\mathcal{I}, \text { for } \mathrm{x}>\mathrm{x}_{\theta}^{*}
\end{array},\right.
$$

where the coefficient $A_{\theta}$ and the investment threshold $x_{\theta}^{*}$ in the last expression are determined from the respective value matching and smooth pasting conditions

$$
\mathrm{A}_{\theta} \times\left(\mathrm{x}_{\theta}^{*}\right)^{\beta_{1}}=\mathrm{g}_{\theta}\left(\mathrm{x}_{\theta}^{*}\right)-\mathcal{I} \text { and } \mathrm{A}_{\theta} \times \beta_{1} \times\left(\mathrm{x}_{\theta}^{*}\right)^{\beta_{1}-1}=\mathrm{g}_{\theta}{ }^{\prime}\left(\mathrm{x}^{*}\right) \text {. }
$$

It is not hard to see that with $\theta=0$ one has $\mathrm{x}_{\theta}^{*}=\mathrm{x}^{*}$ and $\mathrm{q}_{\theta}(\mathrm{x})=\mathrm{q}(\mathrm{x})$.

One must realize that the expressions in (1.5) and in (1.8) are derived under the implicit assumption that the amount of investment capital $I$, which is needed in order to exercise the investment opportunity, is somehow available at no cost of any kind to the owner of the option to invest. The most straight-forward interpretation of this assumption is that if the amount $\mathcal{I}$ is not available to the owner of the project, the owner can borrow $\mathcal{I}$ units of money, create a factory worth $\mathrm{g}\left(\mathrm{X}_{\mathrm{t}}\right)$ units of money, sell the factory for its face value $\mathrm{g}\left(\mathrm{X}_{\mathrm{t}}\right)$, pay back the amount $\mathcal{I}$ and collect the difference $g\left(X_{t}\right)-I$ (since we neglect the amount of time needed to execute this transaction, we also must neglect the fee for borrowing $\mathcal{I}$ units of money). Of course, in practice, large scale projects are not always as liquid as stock options nor is it always possible to borrow a large sum of money instantly and without frictions of any kind. Typically, the holder of a stock option does not need any cash in order to exercise the option - in 
effect, the stock broker transfers the difference between the stock price and the exer: cise price from the account of the holder of the short position in the contract into the account of the holder of the long position in the contract (usually, after collecting transaction fee). In this respect, exercising the option to install a new factory is quite different: somehow, $\mathcal{I}$ units of money must come from somewhere before the new production facility can be established. Thus, when $Y_{t} \leqslant \mathcal{I}$ one would expect that, in general, in a world without taxes, the present value, $\mathrm{V}\left(\mathrm{X}_{\mathrm{t}}, \mathrm{Y}_{\mathrm{t}}\right)$, of the firm with an option to expand must satisfy the relation

$$
\mathrm{V}\left(\mathrm{X}_{\mathrm{t}}, \mathrm{Y}_{\mathrm{t}}\right) \leqslant \mathrm{Y}_{\mathrm{t}}+\mathrm{g}\left(\mathrm{X}_{\mathrm{t}}\right)+\mathrm{q}\left(\mathrm{X}_{\mathrm{t}}\right)
$$

and that the equality in this relation holds only if the firm can raise $\mathcal{I}-\mathrm{Y}_{\mathrm{t}}$ units of money with no frictions of any kind; in particular, the equality must hold if $Y_{t}=\mathcal{I}$, since in this case the firm already has the cash needed to exercise the option to expand - this is exactly the assumption under which the quantity $\mathrm{q}\left(\mathrm{X}_{\mathrm{t}}\right)$ was derived.

It is just as important to point out that the expression in (1.5) is derived under the implicit assumption that the owner of the factory is entitled to the entire profit from operations. The practical aspect of this assumption is that a firm that has already accumulated the amount of cash needed to exercise all known investment opportuni : ties in the future must distribute among its shareholders any additional profit in the form of dividends, or make this profit available to the shareholders as a liquid capital in some other way. Indeed, the share value cannot reflect future cash-flows that are never to be used for expansion and are never to be paid out, since, banning speculative bubbles, the market value of such cash-flows can only be zero. In particular, given that the firm with an option to expand has only one investment opportunity, which can be exercised at the cost of $\mathcal{I}$ units of money, we will suppose that any cash in the firm in excess of the amount $\mathcal{I}$ is immediately distributed among the shareholders.

Finally, we will suppose that, if subject to taxes, the firm's earnings are never doubly taxed and that the tax is applied only to cash that leaves the firm either in the form of dividends or in the form of an expense for new equipment - for example, the fixed cost of new investment, $I$, may include applicable taxes on the purchase of new equipment. Given that in our model the firm's cash is either used for expansion or is paid out to shareholders, this assumption is quite natural. As a result, the retained earnings in the firm with an option to expand can never exceed the amount $I$ and when the retained earnings are exactly equal to $I$, the present value of the firm with an option to expand equals the amount $\mathcal{I}$ plus the present value of the existing factory plus the present value of the (only) option to expand; in other words, one must have

$$
\mathrm{V}\left(\mathrm{X}_{\mathrm{t}}, \mathcal{I}\right)=\mathcal{I}+\mathrm{g}_{\theta}\left(\mathrm{X}_{\mathrm{t}}\right)+\mathrm{q}_{\theta}\left(\mathrm{X}_{\mathrm{t}}\right)
$$

where $\theta \in \llbracket 0,1 \llbracket$ is the tax rate applied to the firm's profits. We will refer to the last relation as «the budget condition». In fact, (1.9) can be derived by using the same type of contingent claims analysis and dynamic programming methods that were used in [4] to derive (1.4), (1.5) and (1.8). Indeed, when $\mathrm{x} \geqslant \mathrm{x}_{\theta}^{*}$, one must have $\mathrm{V}(\mathrm{x}, \mathcal{I})=$ $2 \mathrm{~g}_{\theta}(\mathrm{x})$, since, as long as exercising the investment opportunity is justified, the firm will spend $I$ units of money (in this case, all of its cash) to build the second factory, as a result of which it will end up with two factories and 0 units of money in the bank. It is easy to check that, after taking into account the differential equation for the function $\mathrm{x} \rightarrow \mathrm{V}(\mathrm{x}, \mathcal{I})$ in the interval $\mathrm{x} \in \llbracket 0, \mathrm{x}_{\theta}^{*} \rrbracket$ (see [4]), in conjunction with the value match: ing and the smooth-pasting conditions at $\mathrm{x}=\mathrm{x}_{\theta}^{*}$, one arrives at (1.9). 
When the output price approaches 0 , the firm's business becomes worthless and all that the firm has is its cash. Consequently, the valuation map $\mathrm{V}(\cdot, \cdot)$ must satisfy the following relation, which will be referred to as «the termination condition»

$$
\lim _{\mathrm{x} \triangleleft 0} \mathrm{~V}(\mathrm{x}, \mathrm{y})=\mathrm{y} .
$$

Thus, we need to study the valuation map (1.3) only in the region

$$
\mathcal{R}=\left\{(\mathrm{x}, \mathrm{y}) \in \mathbb{R}^{2} ; \mathrm{x}>0,0 \leqslant \mathrm{y}<\mathcal{I}\right\}
$$

and require that

$$
\lim _{\mathrm{y}>I} \mathrm{~V}(\mathrm{x}, \mathrm{y})=\mathcal{I}+\mathrm{g}_{\theta}(\mathrm{x})+\mathrm{q}_{\theta}(\mathrm{x}),
$$

in addition to the termination condition (1.10).

\section{§2. The Price of the Firm's Money: the Marginal Rate of Substitution of Retained Earnings}

In practice, future investment opportunities and the payoffs from exercising them depend on many random factors. Throughout this paper we will suppose that debt is not available as a financial instrument and that the present value of the option to expand depends only on two factors: the availability of investment capital and the output price. Our goal is to develop some understanding of the way in which the retained earnings and the ability to raise investment capital by selling equity affect shareholders' wealth. Thus, we must answer the question: how much is the firm's money worth from the owner's point of view? In other words, we must compute the marginal rate of substitution of retained earnings (MRSRE), defined as the rate at which the owner of the firm is willing to substitute personal cash for cash in the firm while holding her combined wealth constant. J ust as the present value of the firm is, the MRSRE, too, is a function of the output price $X_{t}>0$ and the retained earnings $Y_{t} \geqslant 0$. Because the MRSRE plays a central role in our study, it deserves a special notation - we will denote this quantity by $\mu$, or by $\mu\left(X_{t}, Y_{t}\right)$ if the dependence on the output price and the retained earnings must be emphasized.

In order to gain some insight in the nature of the MRSRE, suppose that at the present moment the output price is $X_{t}=x>0$, the firm's retained earnings are $Y_{t}=$ $y \geqslant 0$ and the amount of cash in the owner's private account is $z \geqslant 0$. Thus, at the present moment the firm is worth $\mathrm{V}(\mathrm{x}, \mathrm{y})$ units of money, $\mathrm{V}(\cdot, \cdot)$ being the valuation map from (1.3), and the owner's wealth equals $V(x, y)+z$ units of money. Keeping the output price $\mathrm{x}$ fixed, consider the function

$$
(\mathrm{y}, \mathrm{z}) \longrightarrow \mathrm{U}(\mathrm{y}, \mathrm{z}) \equiv \mathrm{V}(\mathrm{x}, \mathrm{y})+\mathrm{z}
$$

and think of it as the owner's utility - the owner cannot control the output price but can put her private money in the firm instantly and at no cost. Since the relation $d \mathrm{U}(\mathrm{y}, \mathrm{z})=0$ is equivalent to

$$
\frac{-d \mathrm{z}}{d \mathrm{y}}=\mathrm{V}^{(0,1)}(\mathrm{x}, \mathrm{y}),
$$

we see that the rate at which the owner is willing to substitute private money for money in the firm, while keeping her total wealth constant is given by

$$
\mathrm{u}(\mathrm{x}, \mathrm{y})=\mathrm{V}^{(0,1)}(\mathrm{x}, \mathrm{y}) \text {. }
$$

2:1 (Remark) For the sake of simplicity, we have chosen to ignore the owners' con: sumption preferences and level of risk tolerance. 
Thus, the calculation of the MRSRE comes down to computing the valuation map in (1.3) and its partial derivative with respect to the retained earnings. Of course, this means that we must express the valuation map in a form that would allow us to compute its derivatives. From the point of view of contingent claims analysis, this boils down to describing the valuation map as the solution to some (free or fixed) boundaryvalue problem for the fundamental pricing equation described below. The actual bound: ary conditions depend on whether the firm is liquid or not and/ or whether taxes and transaction costs apply or not. Later we will show that in the case of a liquid firm in an economy without taxes and transaction costs one has $\mu(x, y) \equiv 1$, i.e., in this case the owner is indifferent between keeping her money in her private account or in the firm. Because of the budget condition, this property is equivalent to

$$
\mathrm{V}(\mathrm{x}, \mathrm{y})=\mathrm{y}+\mathrm{g}(\mathrm{x})+\mathrm{q}(\mathrm{x}) \text { for } \mathrm{x} \geqslant 0 \text { and } 0 \leqslant \mathrm{y} \leqslant \mathcal{I},
$$

and so, it is completely consistent with the Modigliani-Miller theory.

\section{§3. The Price of an Illiquid Firm with an Option to Expand}

"Illiquid" simply means that the firm cannot acquire cash in any way other than retain: ing its earnings - recall that throughout this exposition we suppose that debt is not available as a financial instrument. Assuming that the investment opportunity is yet to be exercised and the retained earnings do not exceed the amount $I$, we will now con: sider the case in which the firm does not pay dividends to its shareholders and retains all profits from operations. Such a firm can be treated as a contingent claim on a two-di: mensional underlying process, namely, the process

$$
\mathbb{R}_{+} \ni \mathrm{t} \longrightarrow\left(\mathrm{X}_{\mathrm{t}}, \mathrm{Y}_{\mathrm{t}}\right) \in \mathbb{R}^{2},
$$

where $X_{t}, t \geqslant 0$, and $Y_{t}, t \geqslant 0$, are governed, respectively, by (1.1) and (1.2). Conse: quently, the valuation map

$$
\mathcal{R} \ni(\mathrm{x}, \mathrm{y}) \longrightarrow \mathrm{V}(\mathrm{x}, \mathrm{y}) \in \mathbb{R}
$$

must satisfy the fundamental pricing equation

$$
\frac{1}{2} \sigma^{2} \mathrm{x}^{2} \mathrm{~V}^{(2,0)}(\mathrm{x}, \mathrm{y})+(\mathrm{r}-\delta) \mathrm{xV}^{(1,0)}(\mathrm{x}, \mathrm{y})+(\pi(\mathrm{x})+\mathrm{ry}) \mathrm{V}^{(0,1)}(\mathrm{x}, \mathrm{y})=\mathrm{rV}(\mathrm{x}, \mathrm{y})
$$

in the entire region $\mathcal{R}$. Two independent derivations of this equation are included in the Appendix. They are based on standard arguments used in contingent claims analy: sis and contain nothing new.

3:1 (Remark) Notice that with $\mathrm{V}^{(0,1)}(\mathrm{x}, \mathrm{y}) \equiv 0$ equation (3.1) turns into the time-inde: pendent version of the standard Black-Scholes equation. In particular, there is a family of solutions to (3.1) that do not depend on the variable $y$. These solutions have the form $V(x, y)=f(x)$, where $x \rightarrow f(x)$ satisfies the second-order equation

$$
\frac{1}{2} \sigma^{2} \mathrm{x}^{2} \mathrm{f}^{\prime \prime}(\mathrm{x})+(\mathrm{r}-\delta) \mathrm{xf}^{\prime}(\mathrm{x})=\mathrm{rf}(\mathrm{x}) \text {. }
$$

It is important to keep in mind that equation (3.1) is based on the assumption that the firm's earnings are not subject to taxes for as long as these earnings remain in the firm. If this is not the case and the firm's earnings are taxed at rate $\theta \in \llbracket 0,1 \llbracket$, then one must replace the coefficient $\pi(\mathrm{x})+\mathrm{ry}$ in $(3.1)$ with $(1-\theta)(\pi(\mathrm{x})+\mathrm{ry})$. This modifica: tion does not affect the procedure for solving equation (3.1) that we are about to describe - one simply has to repeat the same procedure with the function $(\mathrm{x}, \mathrm{y}) \longrightarrow$ $\pi(\mathrm{x})+\mathrm{ry}$ replaced by the function $(\mathrm{x}, \mathrm{y}) \longrightarrow(1-\theta)(\pi(\mathrm{x})+\mathrm{ry})$. We will not deal with this case because we have already made the assumption that the firm's earnings are 
never doubly taxed and that, if taxed, the tax is applied only to cash that leaves the firm either in the form of dividends or as a part of the expense for new equipment, neither of which can occur when $\left(\mathrm{X}_{\mathrm{t}}, \mathrm{Y}_{\mathrm{t}}\right) \in \mathcal{R}$.

Our next goal is to find the only solution to (3.1) that satisfies the termination condition (1.10) and the budget condition (1.11). To simplify the notation, we will write $\mathrm{V}(\mathrm{x}, \mathcal{I})$ instead of $\mathcal{I}+\mathrm{g}_{\theta}(\mathrm{x})+\mathrm{q}_{\theta}(\mathrm{x})$.

In order to develop some intuition about the general solution to the pricing equation (3.1), notice first that with the substitutions $\mathrm{x}=e^{\sigma \xi}$ and

$$
\mathrm{u}(\xi, \mathrm{y})=e^{-\frac{\xi\left(\sigma^{2}-2 \mathrm{r}+2 \delta\right)}{2 \sigma}} \mathrm{V}\left(e^{\sigma \xi}, \mathrm{y}\right),
$$

equation (3.1) becomes

$$
\frac{1}{2} \mathrm{u}^{(2,0)}(\xi, \mathrm{y})+\left(\pi\left(e^{\xi \sigma}\right)+\mathrm{ry}\right) \mathrm{u}^{(0,1)}(\xi, \mathrm{y})=\kappa \mathrm{u}(\xi, \mathrm{y}),
$$

where

$$
\kappa=\frac{\sigma^{4}+4 \sigma^{2}(\mathrm{r}+\delta)+4(\mathrm{r}-\delta)^{2}}{8 \sigma^{2}}>0 .
$$

It is not hard to show that for every integer $\mathrm{n} \in \mathbb{Z}_{+}$one can find a family of solutions to (3.2) that have the form

$$
\mathrm{u}(\xi, \mathrm{y})=\mathrm{v}_{0}(\xi)+\mathrm{yv}_{1}(\xi)+\mathrm{y}^{2} \mathrm{v}_{2}(\xi)+\ldots+\mathrm{y}^{\mathrm{n}} \mathrm{v}_{\mathrm{n}}(\xi), \mathrm{y} \in \mathbb{R}_{+}, \quad \xi \in \mathbb{R},
$$

for some appropriate choice of twice differentiable functions $\xi \rightarrow \mathrm{v}_{\mathrm{i}}(\xi), \mathrm{i}=1, \ldots, \mathrm{n}$. For example, if $\mathrm{u}(\cdot, \cdot)$ is given by (3.3) with $\mathrm{n}=3$, then (3.2) becomes

$$
\begin{aligned}
&\left(3 \mathrm{rv}_{3}(\xi)-\kappa \mathrm{v}_{3}(\xi)\right.\left.+\frac{1}{2} \mathrm{v}_{3}^{\prime \prime}(\xi)\right) \mathrm{y}^{3} \\
&+\left(2 \mathrm{rv}_{2}(\xi)-\kappa \mathrm{v}_{2}(\xi)+3 \pi\left(e^{\xi \sigma}\right) \mathrm{v}_{3}(\xi)+\frac{1}{2} \mathrm{v}_{2}^{\prime \prime}(\xi)\right) \mathrm{y}^{2} \\
&+\left(\mathrm{rv}_{1}(\xi)-\kappa \mathrm{v}_{1}(\xi)+2 \pi\left(e^{\xi \sigma}\right) \mathrm{v}_{2}(\xi)+\frac{1}{2} \mathrm{v}_{1}^{\prime \prime}(\xi)\right) \mathrm{y} \\
&+\pi\left(e^{\xi \sigma}\right) \mathrm{v}_{1}(\xi)-\kappa \mathrm{v}_{0}(\xi)+\frac{1}{2} \mathrm{v}_{0}^{\prime \prime}(\xi)=0 .
\end{aligned}
$$

It is not hard to see how one can choose the functions $\mathrm{v}_{0}(\cdot), \mathrm{v}_{1}(\cdot), \mathrm{v}_{2}(\cdot)$ and $\mathrm{v}_{3}(\cdot)$ so that the last equation is satisfied: first, one can $\operatorname{choose~}_{3}(\cdot)$ so that

$$
3 \mathrm{rv}_{3}(\xi)-\kappa \mathrm{v}_{3}(\xi)+\frac{1}{2} \mathrm{v}_{3}^{\prime \prime}(\xi)=0,
$$

then one can $\operatorname{choose~}_{2}(\cdot)$ so that

$$
2 \mathrm{rv}_{2}(\xi)-\kappa \mathrm{v}_{2}(\xi)+3 \pi\left(e^{\xi \sigma}\right) \mathrm{v}_{3}(\xi)+\frac{1}{2} \mathrm{v}_{2}^{\prime \prime}(\xi)=0,
$$

then one can $\operatorname{choose~}_{1}(\cdot)$ so that

$$
\mathrm{rv}_{1}(\xi)-\kappa \mathrm{v}_{1}(\xi)+2 \pi\left(e^{\xi \sigma}\right) \mathrm{v}_{2}(\xi)+\frac{1}{2} \mathrm{v}_{1}^{\prime \prime}(\xi)
$$

and, finally, one can $\operatorname{choose~}_{0}(\cdot)$ so that

$$
\pi\left(e^{\xi \sigma}\right) \mathrm{v}_{1}(\xi)-\kappa \mathrm{v}_{0}(\xi)+\frac{1}{2} \mathrm{v}_{0}^{\prime \prime}(\xi)=0 .
$$

In general, every solution of the form (3.3) depends on $2 \mathrm{n}$ independent param: eters. In particular, one can find solutions to (3.2) that happen to be affine functions of the variable $y$ when the variable $\xi$ is fixed. Such solutions must have the form $u(\xi, y)=$ $\mathrm{v}_{0}(\xi)+\mathrm{y}_{1}(\xi)$, where $\mathrm{v}_{0}(\cdot)$ and $\mathrm{v}_{1}(\cdot)$ satisfy the following system of ordinary differen: tial equations: 


$$
\mathrm{rv}_{1}(\xi)-\kappa \mathrm{v}_{1}(\xi)+\frac{1}{2} \mathrm{v}_{1}^{\prime \prime}(\xi)=0 \text { and } \pi\left(e^{\xi \sigma}\right) \mathrm{v}_{1}(\xi)-\kappa \mathrm{v}_{0}(\xi)+\frac{1}{2} \mathrm{v}_{0}^{\prime \prime}(\xi)=0
$$

Since

$$
\kappa-\mathrm{r}=\frac{\left(\sigma^{2}-2 \mathrm{r}+2 \delta\right)^{2}}{8 \sigma^{2}} \geqslant 0,
$$

the function $\mathrm{v}_{1}(\cdot)$ must be of the form

$$
\mathrm{V}_{1}(\xi)=\mathrm{C}_{1} e^{\sqrt{2(\kappa-\mathrm{r})} \xi}+\mathrm{C}_{2} e^{-\sqrt{2(\kappa-\mathrm{r})} \xi}=\mathrm{C}_{1} e^{\frac{\sigma^{2}-2 \mathrm{r}+2 \delta}{2 \sigma} \xi}+\mathrm{C}_{2} e^{-\frac{\sigma^{2}-2 \mathrm{r}+2 \delta}{2 \sigma} \xi},
$$

for some choice of the constants $\mathrm{C}_{1}, \mathrm{C}_{2} \in \mathbb{R}$. With this choice of $\mathrm{v}_{1}(\cdot)$ one has

$$
\begin{aligned}
\mathrm{V}(\mathrm{x}, \mathrm{y}) \equiv \mathrm{V}\left(e^{\sigma \xi}, \mathrm{y}\right) & =e^{\frac{\sigma^{2}-2 \mathrm{r}+2 \delta}{2 \sigma} \xi} \times\left(\mathrm{V}_{0}(\xi)+\mathrm{V}_{1}(\xi) \mathrm{y}\right) \\
& =e^{\frac{\sigma^{2}-2 \mathrm{r}+2 \delta}{2 \sigma} \xi} \times \mathrm{V}_{0}(\xi)+\left(\mathrm{C}_{1} e^{\frac{\sigma^{2}-2 \mathrm{r}+2 \delta}{\sigma} \xi}+\mathrm{C}_{2}\right) \times \mathrm{y} .
\end{aligned}
$$

Consequently, by choosing $\mathrm{C}_{1}=0$ and $\mathrm{C}_{2}=1$ one can find solutions to (3.1) that have the form

$$
\mathrm{V}(\mathrm{x}, \mathrm{y})=e^{\frac{\sigma^{2}-2 \mathrm{r}+2 \delta}{2 \sigma} \times \frac{\log \mathrm{x})}{\sigma}} \times \mathrm{v}_{0}\left(\frac{\log (\mathrm{x})}{\sigma}\right)+\mathrm{y}=\mathrm{x}^{\frac{\sigma^{2}-2 \mathrm{r}+2 \delta}{2 \sigma^{2}}} \times \mathrm{v}_{0}\left(\frac{\log (\mathrm{x})}{\sigma}\right)+\mathrm{y} .
$$

Such solutions are interesting because they have the property $\mu(x, y) \equiv V^{(0,1)}(x, y)=1$ - this is exactly the class of solutions in which the marginal rate of substitution of retained earnings is identical to the constant 1 . With $\mathrm{C}_{1}=0$ and $\mathrm{C}_{2}=1$ one has $\mathrm{v}_{1}(\xi) \equiv$ $e^{-\frac{\sigma^{2}-2 \mathrm{r}+2 \delta}{2 \sigma} \xi}$, so that $\mathrm{v}_{0}(\cdot)$ can be found from the equation

$$
\pi\left(e^{\xi \sigma}\right) \times e^{-\frac{\sigma^{2}-2 \mathrm{r}+2 \delta}{2 \sigma} \xi}-\kappa \mathrm{V}_{0}(\xi)+\frac{1}{2} \mathrm{v}_{0}^{\prime \prime}(\xi)=0 .
$$

In particular, for $\xi \leqslant \frac{1}{\sigma} \log (c)$ one has $\pi\left(e^{\xi \sigma}\right)=0$ and therefore

$$
\mathrm{v}_{0}(\xi)=\mathrm{C}_{3} e^{\sqrt{2 \kappa} \xi}+\mathrm{C}_{4} e^{-\sqrt{2 \kappa} \xi} \text { for }-\infty<\xi \leqslant \frac{1}{\sigma} \log (c) .
$$

Thus, for $0 \leqslant \mathrm{x} \leqslant c$ one must have

$$
\mathrm{V}(\mathrm{x}, \mathrm{y})=\mathrm{C}_{3} \mathrm{x}^{\frac{\sigma^{2}-2 r+2 \delta}{2 \sigma^{2}}+\frac{1}{\sigma} \sqrt{2 \kappa}}+\mathrm{C}_{4} \mathrm{x}^{\frac{\sigma^{2}-2 \mathrm{r}+2 \delta}{2 \sigma^{2}}-\frac{1}{\sigma} \sqrt{2 \kappa}}+\mathrm{y} .
$$

It is a trivial matter to check that

$$
\sigma^{4}+4(\mathrm{r}+\delta) \sigma^{2}+4(\mathrm{r}-\delta)^{2}-\left(\sigma^{2}-2 \mathrm{r}+2 \delta\right)^{2}=8 \mathrm{r} \sigma^{2}>0,
$$

which implies that

$$
\frac{1}{\sigma} \sqrt{2 \kappa}=\frac{\sqrt{\sigma^{4}+4(\mathrm{r}+\delta) \sigma^{2}+4(\mathrm{r}-\delta)^{2}}}{2 \sigma^{2}}>\frac{\sigma^{2}-2 \mathrm{r}+2 \delta}{2 \sigma^{2}} .
$$

In conjunction with the termination condition (1.10), this estimate implies that the constant $\mathrm{C}_{4}$ in (3.5) must be set to 0 . Thus, the termination condition, together with the requirement that $\mu(\mathrm{x}, \mathrm{y}) \equiv 1$, implies that

$$
\mathrm{V}(\mathrm{x}, \mathrm{y})=\mathrm{C}_{3} \mathrm{x}^{\frac{\sigma^{2}-2 \mathrm{r}+2 \delta}{2 \sigma^{2}}+\frac{1}{\sigma} \sqrt{2 \kappa}}+\mathrm{y} \equiv \mathrm{C}_{3} \mathrm{x}^{\beta_{1}}+\mathrm{y}, \text { for } 0 \leqslant \mathrm{x} \leqslant c,
$$

where

$$
\beta_{1}=\frac{\sigma^{2}-2 \mathrm{r}+2 \delta}{2 \sigma^{2}}+\frac{1}{\sigma} \sqrt{2 \kappa}=\frac{\sigma^{2}-2 \mathrm{r}+2 \delta+\sqrt{8 \mathrm{r} \sigma^{2}+\left(-\sigma^{2}+2 \mathrm{r}-2 \delta\right)^{2}}}{2 \sigma^{2}}
$$

is the largest (automatically positive) root of the fundamental quadratic equation

$$
\frac{1}{2} \sigma^{2}(\beta-1) \beta+(\mathrm{r}-\delta) \beta=\mathrm{r} .
$$

Returning to equation (3.4), one sees that for $\xi>\frac{1}{\sigma} \log (c)$ this equation becomes 


$$
\left(e^{\xi \sigma}-c\right) \times e^{-\frac{\sigma^{2}-2 \mathrm{r}+2 \delta}{2 \sigma} \xi}-\kappa \mathrm{V}_{0}(\xi)+\frac{1}{2} \mathrm{v}_{0}^{\prime \prime}(\xi)=0,
$$

and therefore has a family of solutions that can be described as

$$
\frac{1}{\delta} e^{\frac{\sigma^{2}+2 \mathrm{r}-2 \delta}{2 \sigma} \xi}-\frac{c}{\mathrm{r}} e^{\frac{-\sigma^{2}+2 \mathrm{r}-2 \delta}{2 \sigma} \xi}+\mathrm{C}_{5} e^{\sqrt{2 \kappa} \xi}+\mathrm{C}_{6} e^{-\sqrt{2 \kappa} \xi},
$$

for all possible choices of the constants $\mathrm{C}_{5}, \mathrm{C}_{6} \in \mathbb{R}$. Thus, the termination condition, together with the requirement that $\mu(\mathrm{x}, \mathrm{y}) \equiv 1$, implies that for $\mathrm{x}>c$ the solution to (3.1) must be of the form (recall that $\mathrm{x}=e^{\sigma \xi} \Longleftrightarrow \xi=\frac{1}{\sigma} \log (\mathrm{x})$ )

$$
\begin{aligned}
& \mathrm{V}(\mathrm{x}, \mathrm{y})= \mathrm{x}^{\frac{\sigma^{2}-2 \mathrm{r}+2 \delta}{2 \sigma^{2}}}\left(\frac{1}{\delta} \mathrm{x}^{\frac{\sigma^{2}+2 \mathrm{r}-2 \delta}{2 \sigma^{2}}}-\frac{c}{\mathrm{r}} \mathrm{x}^{\frac{-\sigma^{2}+2 \mathrm{r}-2 \delta}{2 \sigma^{2}}}+\mathrm{C}_{5} \mathrm{x}^{\frac{1}{\sigma} \sqrt{2 \kappa}}\right. \\
&\left.+\mathrm{C}_{6} \mathrm{x}^{-\frac{1}{\sigma} \sqrt{2 \kappa}}+\mathrm{x}^{-\frac{\sigma^{2}-2 \mathrm{r}+2 \delta}{2 \sigma^{2}}} \mathrm{y}\right) \\
&=\frac{\mathrm{x}}{\delta}-\frac{c}{\mathrm{r}}+\mathrm{C}_{5} \mathrm{x}^{\frac{\sigma^{2}-2 \mathrm{r}+2 \delta}{2 \sigma^{2}}+\frac{1}{\sigma} \sqrt{2 \kappa}}+\mathrm{C}_{6} \mathrm{x}^{\frac{\sigma^{2}-2 \mathrm{r}+2 \delta}{2 \sigma^{2}}-\frac{1}{\sigma} \sqrt{2 \kappa}}+\mathrm{y} .
\end{aligned}
$$

The terms involving the variable $\mathrm{x}$ in the last expression can be interpreted exactly in the way these terms are interpreted in [4]: the quantity $\frac{x}{\delta}-\frac{c}{r}$ represents the funda: mental value of the factory when the output price equals $\mathrm{x}$ and the quantity

$$
\mathrm{C}_{5} \mathrm{x}^{\frac{\sigma^{2}-2 \mathrm{r}+2 \delta}{2 \sigma^{2}}+\frac{1}{\sigma} \sqrt{2 \kappa}}+\mathrm{C}_{6} \mathrm{x}^{\frac{\sigma^{2}-2 \mathrm{r}+2 \delta}{2 \sigma^{2}}-\frac{1}{\sigma} \sqrt{2 \kappa}}
$$

represents the value of the option to suspend production when the output price falls below the production cost $c$. Since this option becomes worthless when $\mathrm{x} \lambda \infty$, one must set $\mathrm{C}_{5}=0$. It is easy to check that

$$
\beta_{2}:=\frac{\sigma^{2}-2 \mathrm{r}+2 \delta}{2 \sigma^{2}}-\frac{1}{\sigma} \sqrt{2 \kappa}=\frac{\sigma^{2}-2 \mathrm{r}+2 \delta-\sqrt{8 \mathrm{r} \sigma^{2}+\left(-\sigma^{2}+2 \mathrm{r}-2 \delta\right)^{2}}}{2 \sigma^{2}}
$$

is the smallest (automatically negative) root of the fundamental quadratic equation

$$
\frac{1}{2} \sigma^{2}(\beta-1) \beta+(\mathrm{r}-\delta) \beta=\mathrm{r} .
$$

Just as this was done in [4] when the valuation map $x \rightarrow g(x)$ was calculated, the constants $\mathrm{C}_{3}$ in (3.5) and $\mathrm{C}_{6}$ in (3.6) can be determined by the value matching and smooth pasting conditions with respect to the variable $\mathrm{x}$ at $\mathrm{x}=c$. Thus, the termina: tion condition and the requirement $\mu(\mathrm{x}, \mathrm{y}) \equiv 1$ lead to a unique solution given by

$$
\mathrm{V}(\mathrm{x}, \mathrm{y})=\mathrm{g}(\mathrm{x})+\mathrm{y} \text {, }
$$

where $\mathrm{g}(\mathrm{x})$ is given by (1.4). Of course, with this solution one has

$$
\lim _{\mathrm{y}>I} \mathrm{~V}(\mathrm{x}, \mathrm{y})=\mathrm{g}(\mathrm{x})+\mathcal{I}<\mathrm{q}(\mathrm{x})+\mathrm{g}(\mathrm{x})+\mathcal{I}
$$

which shows that one cannot hope to find a solution to (3.1) that has the property $\mu(x, y) \equiv 1$ and, at the same time, satisfies the budget condition (1.11) and the termina: tion condition (1.10).

3:2 (Remark) The above argument shows that looking for a solution to the fundamen: tal pricing equation (3.1) that satisfies the termination condition (1.10) and the require: ment $\mu(\mathrm{x}, \mathrm{y}) \equiv \mathrm{V}^{(0,1)}(\mathrm{x}, \mathrm{y}) \equiv 1$ is the same as looking for a solution that satisfies the termination condition and the boundary condition $\lim _{\mathrm{y} \lambda I} \mathrm{~V}(\mathrm{x}, \mathrm{y})=\mathrm{g}(\mathrm{x})+\mathcal{I}$. How: ever, this last condition simply says that the owner of the production facility has no option to invest. Thus, assuming that the termination condition is always in force, the only case in which the marginal rate of substitution of retained earnings for an illiquid firm is identically equal to 1 is the one in which the firm has no option to invest. This is completely consistent with the intuition: if the firm has the ability to create new 
wealth and the retained earnings are the only investment capital available for expan: sion, any increase in the retained earnings does more than just adding wealth to the firm: it increases the firm's capability to create new wealth. The valuation map $\mathrm{x} \rightarrow \mathrm{g}(\mathrm{x})$ given by (1.4), which gives the value of a single factory as a function of the output price, was derived in [4] under the implicit assumption that the owner of the production facility has no option to invest. Indeed, looking for a function $\mathrm{x} \longrightarrow \mathrm{g}(\mathrm{x})$ that solves the equation

$$
\frac{1}{2} \sigma^{2} \mathrm{x}^{2} \mathrm{~g}^{\prime \prime}(\mathrm{x})+(\mathrm{r}-\delta) \mathrm{x} \mathrm{g}^{\prime}(\mathrm{x})+\pi(\mathrm{x})=\mathrm{rg}(\mathrm{x})
$$

is tantamount to looking for a function $(x, y) \rightarrow V(x, y)=g(x)+y$ that solves the fundamental pricing equation (3.1).

Unfortunately, finding a closed form solution to the fundamental pricing equation (3.1) that satisfies the budget condition (1.11) and the termination condition (1.10) doesn't seem possible. Thus, one must develop a numerical procedure that yields an approximate solution. One possibility is to fix some sufficiently large $n \geqslant 1$ and approximate the actual solution with a solution of the form (3.3). As explained earlier, (3.3) actually represents a $2 \mathrm{n}$-parameter family of solutions. Thus - on principle, at least - one can use parameter fitting to find a solution that best fits the budget condi: tion and the termination condition. However, we will develop a different method that is somewhat easier to implement numerically and is easier to interpret from the point of view of economics. This method is based on the idea that in a small neighborhood of any given point $(\mathrm{a}, \mathrm{b}) \in \mathbb{R}_{+} \times \mathbb{R}_{++}$a function $(\mathrm{x}, \mathrm{y}) \rightarrow \mathrm{U}(\mathrm{x}, \mathrm{y})$ that satisfies the equation

$$
\frac{1}{2} \sigma^{2} \mathrm{x}^{2} \mathrm{U}^{(2,0)}(\mathrm{x}, \mathrm{y})+(\mathrm{r}-\delta) \mathrm{x} \mathrm{U}^{(1,0)}(\mathrm{x}, \mathrm{y})+(\pi(\mathrm{a})+\mathrm{rb}) \mathrm{U}^{(0,1)}(\mathrm{x}, \mathrm{y})=\mathrm{r} \mathrm{U}(\mathrm{x}, \mathrm{y})
$$

"almost" satisfies equation (3.1). Notice that (3.7) is essentially the standard Black-Sc: holes equation with y playing the rôle of a re-scaled time-variable. Indeed, after the substitution $\mathrm{y} \equiv \mathrm{y}(\mathrm{t}):=(\pi(\mathrm{a})+\mathrm{rb}) \times \mathrm{t}$ and $\mathrm{u}(\mathrm{x}, \mathrm{t}):=\mathrm{U}(\mathrm{x}, \mathrm{y}(\mathrm{t}))$, (3.7) becomes

$$
\frac{1}{2} \sigma^{2} \mathrm{x}^{2} \mathrm{u}^{(2,0)}(\mathrm{x}, \mathrm{t})+(\mathrm{r}-\delta) \mathrm{x} \mathrm{u}^{(1,0)}(\mathrm{x}, \mathrm{t})+\mathrm{u}^{(0,1)}(\mathrm{x}, \mathrm{t})=\mathrm{ru}(\mathrm{x}, \mathrm{t}) .
$$

Consequently, (3.7) can be solved in any region of the form $\{(\mathrm{x}, \mathrm{y}) ; \mathrm{x}>0, \mathrm{y}<\hat{\mathrm{y}}\}$, for some fixed $0<\hat{\mathrm{y}} \leqslant \mathcal{I}$ with boundary conditions prescribed at the line $\mathrm{y}=\hat{\mathrm{y}}$. In fact, by the Feynman-Kac formula, for every choice of $\mathrm{x}>0$ and $\mathrm{y}<\hat{\mathrm{y}}$ one must have

$$
\mathrm{U}(\mathrm{x}, \mathrm{y})=e^{-\mathrm{r} \tau} \mathrm{E}\left[\mathrm{U}\left(\mathrm{x} e^{\sigma \beta_{\tau}+\left(\mathrm{r}-\delta-\frac{1}{2} \sigma^{2}\right) \tau}, \hat{\mathrm{y}}\right)\right] \text {, where } \tau:=\frac{\hat{\mathrm{y}}-\mathrm{y}}{\pi(\mathrm{a})+\mathrm{rb}} .
$$

3:4 (Remark) This last identity admits an interesting economic interpretation, for (3.8) is nothing but a special case of the Black-Scholes option pricing formula. Indeed, if the firm collects money at a fixed rate of $\pi(a)+r b$ units of money per unit of time, then the amount of time that it will take to raise the level of retained earnings from the amount $y$ to the amount $\hat{y}>y$ is exactly $\frac{\hat{y}-y}{\pi(a)+r b}$ units of money. Consequently, (3.8) is simply saying that when the output price equals $x$ units of money and the level of retained earnings equals $y$ units of money, the value of the firm can be identified with the price of an European option that expires after $\tau=\frac{\hat{y}-\mathrm{y}}{\pi(\mathrm{a})+\mathrm{rb}}$ units of time and yields the payoff of $\mathrm{U}\left(\mathrm{X}_{\tau}^{\mathrm{x}}, \hat{\mathrm{y}}\right)$, where $\mathrm{X}_{\tau}^{\mathrm{x}}$ stands for the (stochastic) output price after $\tau$ units of time, assuming that the current price is $\mathrm{x}$. 
We will approximate the solution to equation (3.1) with a function defined by way of polynomial interpolation from the assignment

$$
\left(\mathrm{x}_{\mathrm{i}}, \mathrm{y}_{\mathrm{j}}\right) \longrightarrow \mathrm{v}_{\mathrm{i}, \mathrm{j}} \in \mathbb{R}, 0 \leqslant \mathrm{i} \leqslant \mathrm{m}, 0 \leqslant \mathrm{j} \leqslant \mathrm{n},
$$

in a rectangular region of the form $\llbracket 0, \mathrm{~A} \rrbracket \times \llbracket \epsilon, I \rrbracket$, for some fixed $\mathrm{A}>0$ and $0<\epsilon<\mathcal{I}$ and some sufficiently dense grid

$$
0=\mathrm{x}_{0}<\mathrm{x}_{1}<\ldots<\mathrm{x}_{\mathrm{m}}=\mathrm{A}, \epsilon=\mathrm{y}_{0}<\mathrm{y}_{1}<\ldots<\mathrm{y}_{\mathrm{n}}=\mathcal{I} .
$$

In fact, we will set

$$
\mathrm{y}_{\mathrm{j}}=(1+\mathrm{rd})^{-(\mathrm{n}-\mathrm{j})} \times \mathcal{I}, 0 \leqslant \mathrm{j} \leqslant \mathrm{n} \text {, with } \mathrm{d}=\frac{1}{\mathrm{r}}\left(\left(\frac{\mathcal{I}}{\epsilon}\right)^{1 / \mathrm{n}}-1\right) .
$$

The values $v_{i, j}$ will be computed by using the Black-Scholes formula (3.8) in some neighborhood of the point $\left(\mathrm{x}_{\mathrm{i}}, \mathrm{y}_{\mathrm{j}}\right)$. More specifically, we will compute the lists of values $\mathrm{v}_{\mathrm{.}, \mathrm{j}}$ consecutively for $\mathrm{j}=\mathrm{n}, \mathrm{n}-1, \ldots, 0$, by using a recursive procedure that we will now describe. First, one must incorporate the budget condition into the procedure by setting

$$
\mathrm{v}_{\mathrm{i}, \mathrm{n}}=\mathrm{V}\left(\mathrm{x}_{\mathrm{i}}, \mathcal{I}\right) \equiv \mathcal{I}+\mathrm{q}_{\theta}\left(\mathrm{x}_{\mathrm{i}}\right)+\mathrm{g}_{\theta}\left(\mathrm{x}_{\mathrm{i}}\right), 1 \leqslant \mathrm{i} \leqslant \mathrm{m} .
$$

Notice that $\mathrm{v}_{0, \mathrm{n}}=\mathcal{I}$. Next, suppose that the list $\mathrm{v}_{\mathrm{r}, \mathrm{j}}$ has already been calculated and let $\mathrm{x} \rightarrow \mathrm{f}_{\mathrm{j}}(\mathrm{x})$ be the function constructed by way of polynomial interpolation from the assignment $x_{i} \rightarrow v_{i, j}, 0 \leqslant i \leqslant m$. We will treat $f_{j}(\cdot)$ as an approximation of the of the function $\mathrm{x} \rightarrow \mathrm{V}\left(\mathrm{x}, \mathrm{y}_{\mathrm{j}}\right)$, where $\mathrm{V}(\cdot, \cdot)$ is the actual solution to (3.1). The list $\mathrm{v}_{\mathrm{.}, \mathrm{j}-1}$ will be computed as a function of the list $v_{., j}$ described by the rûle

$$
\begin{aligned}
\mathrm{v}_{\mathrm{i}, \mathrm{j}-1}=e^{-\mathrm{r} \tau_{\mathrm{j}}} \mathrm{E}\left[\mathrm{f}_{\mathrm{j}}\left(\mathrm{x}_{\mathrm{i}} e^{\sigma{\mathrm{S}_{\mathrm{j}}}_{\mathrm{j}}+\left(\mathrm{r}-\delta-\frac{1}{2} \sigma^{2}\right) \tau_{\mathrm{j}}}\right)\right], \\
\text { where, } \tau_{\mathrm{j}}:=\frac{\mathrm{y}_{\mathrm{j}}-\mathrm{y}_{\mathrm{j}-1}}{\pi\left(\mathrm{x}_{\mathrm{i}}\right)+\mathrm{r} \mathrm{y}_{\mathrm{j}-1}}, 1 \leqslant \mathrm{i} \leqslant \mathrm{m} .
\end{aligned}
$$

Notice that if the function $f_{j}(\cdot)$ satisfies the termination condition with error $o(d)$, i.e., if $\mathrm{f}_{\mathrm{j}}(0)=\lim _{\mathrm{x} \backslash 0} \mathrm{f}_{\mathrm{j}}(\mathrm{x})=\mathrm{y}_{\mathrm{j}}+\mathrm{O}(\mathrm{d})$, then

$$
\begin{gathered}
\lim _{\mathrm{x}_{\mathrm{i}} \triangleleft 0} e^{-\mathrm{r} \tau_{\mathrm{j}}} \mathrm{E}\left[\mathrm{f}_{\mathrm{j}}\left(\mathrm{x}_{\mathrm{i}} e^{\sigma{\mathrm{S}_{\mathrm{j}}}_{\mathrm{j}}+\left(\mathrm{r}-\delta-\frac{1}{2} \sigma^{2}\right) \tau_{\mathrm{j}}}\right)\right]=e^{-\mathrm{dr}}\left(\mathrm{y}_{\mathrm{j}}+\mathrm{o}(\mathrm{d})\right) \\
=\left((1+\mathrm{dr})^{-1}+\mathrm{o}(\mathrm{d})\right) \times\left(\mathrm{y}_{\mathrm{j}}+\mathrm{o}(\mathrm{d})\right)=\mathrm{y}_{\mathrm{j}-1}+\mathrm{o}(\mathrm{d}),
\end{gathered}
$$

so that the function $f_{j-1}(\cdot)$ constructed by way of polynomial interpolation from the assignment $\mathrm{x}_{\mathrm{i}} \longrightarrow \mathrm{v}_{\mathrm{i}, \mathrm{j}-1}, 0 \leqslant \mathrm{i} \leqslant \mathrm{m}$ also must satisfy the termination condition with error $\mathrm{o}(\mathrm{d})$.

To justify the procedure the we just described, suppose that the solution (x,y) $\rightarrow \mathrm{V}(\mathrm{x}, \mathrm{y})$ has already been computed in the region $\mathcal{R}_{\mathrm{j}}:=\left\{(\mathrm{x}, \mathrm{y}) ; \mathrm{x}>0, \mathcal{I}>\mathrm{y} \geqslant \mathrm{y}_{\mathrm{j}}\right\}$ in such a way that the budget condition and the termination condition are both satis: fied in that region. The value $\mathrm{V}\left(\mathrm{x}_{\mathrm{i}}, \mathrm{y}_{\mathrm{j}-1}\right)$, associated with the point $\left(\mathrm{x}_{\mathrm{i}}, \mathrm{y}_{\mathrm{j}-1}\right)$ which is right below the region $\mathcal{R}_{\mathrm{j}}$ can be computed by solving (3.1) in the region

$$
\mathcal{R}_{\mathrm{j}-1} \backslash \mathcal{R}_{\mathrm{j}}=\left\{(\mathrm{x}, \mathrm{y}) ; \mathrm{x}>0, \mathrm{y}_{\mathrm{j}-1} \leqslant \mathrm{y}<\mathrm{y}_{\mathrm{j}}\right\}
$$

with the following boundary conditions

$$
\lim _{\mathrm{y}>\mathrm{y}_{\mathrm{j}}} \mathrm{V}(\mathrm{x}, \mathrm{y})=\mathrm{V}\left(\mathrm{x}, \mathrm{y}_{\mathrm{j}}\right) \text { and } \lim _{\mathrm{x} \succ 0} \mathrm{~V}(\mathrm{x}, \mathrm{y})=\mathrm{y} .
$$

Thus, for any fixed $\mathrm{x}>0$ and $0<\mathrm{y}<\mathrm{y}_{\mathrm{j}}$, the quantity $\mathrm{V}(\mathrm{x}, \mathrm{y}) \in \mathbb{R}$ can be treated as a function of the infinite dimensional list of values $V\left(x, y_{j}\right), x \in \mathbb{R}_{+}$. Clearly, when the difference $\left(y_{j}-y_{j-1}\right)$ is sufficiently small, given any $x_{i}>0$, the quantity $V\left(x_{i}, y_{j-1}\right)$ will 
depend almost exclusively only on a small portion of the list $\mathrm{V}\left(\mathrm{x}, \mathrm{y}_{\mathrm{j}}\right), \mathrm{x} \in \mathbb{R}_{+}$, namely, it will depend almost exclusively only on the values $\mathrm{V}\left(\mathrm{x}, \mathrm{y}_{\mathrm{j}}\right), \mathrm{x}_{\mathrm{i}}-\varepsilon<\mathrm{x}<\mathrm{x}_{\mathrm{i}}+\varepsilon$, for some small $\varepsilon>0$ which can be made arbitrarily small if the difference $\left(\mathrm{y}_{\mathrm{j}}-\mathrm{y}_{\mathrm{j}-1}\right)$ is sufficiently small. In other words, the quantity $\mathrm{V}\left(\mathrm{x}_{\mathrm{i}}, \mathrm{y}_{\mathrm{j}-1}\right)$ can be computed approxi: mately by solving (3.1) only in a small neighborhood of the point $\left(\mathrm{x}_{\mathrm{i}}, \mathrm{y}_{\mathrm{j}-1}\right)$, where the solution to (3.1) can be approximated by the solution to (3.7). Therefore, instead of computing the quantities $\mathrm{V}\left(\mathrm{x}_{\mathrm{i}}, \mathrm{y}_{\mathrm{j}-1}\right), 1 \leqslant \mathrm{i} \leqslant \mathrm{m}$, by solving (3.1) with boundary condi: tions given by (3.11), we will compute these quantities approximately by solving (3.7) with the following boundary conditions

$$
\lim _{\mathrm{y}>\mathrm{y}_{\mathrm{j}}} \mathrm{U}(\mathrm{x}, \mathrm{y})=\mathrm{f}_{\mathrm{j}}(\mathrm{x}) \text { and } \lim _{\mathrm{x} \triangleleft 0} \mathrm{U}(\mathrm{x}, \mathrm{y})=\mathrm{y} \text {, }
$$

after which each quantity $\mathrm{U}\left(\mathrm{x}_{\mathrm{i}}, \mathrm{y}_{\mathrm{j}-1}\right)$ will be treated as an approximation of the quan: tity $\mathrm{V}\left(\mathrm{x}_{\mathrm{i}}, \mathrm{y}_{\mathrm{j}-1}\right)$ and we will set $\mathrm{v}_{\mathrm{i}, \mathrm{j}-1}=\mathrm{U}\left(\mathrm{x}_{\mathrm{i}}, \mathrm{y}_{\mathrm{j}-1}\right)$ for $1 \leqslant \mathrm{i} \leqslant \mathrm{m}$. It should be clear that if the grid $y_{j}, 1 \leqslant j \leqslant n$, is chosen so that its mesh $\operatorname{Max}\left\{y_{j}-y_{j-1} ; 1 \leqslant j \leqslant n\right\}$ is suffi: ciently small and if the approximation of the function $\mathrm{x} \longrightarrow \mathrm{V}\left(\mathrm{x}, \mathrm{y}_{\mathrm{j}}\right)$ in terms of polyno: mial interpolation from the assignment $x_{i} \longrightarrow v_{i, j}, 1 \leqslant i \leqslant m$, is sufficiently accurate, then the values $\mathrm{v}_{\mathrm{i}, \mathrm{j}-1}$ can be made arbitrarily close to the values $\mathrm{V}\left(\mathrm{x}_{\mathrm{i}}, \mathrm{y}_{\mathrm{j}-1}\right)$.

3:5 (Remark) It is not hard to see the analogy between the procedure that we just described and the standard finite-difference scheme for solving the heat equation

$$
\mathrm{u}^{(0,1)}(\mathrm{x}, \mathrm{t})+\frac{1}{2} \mathrm{u}^{(2,0)}(\mathrm{x}, \mathrm{t})=0
$$

in the region $\{(\mathrm{x}, \mathrm{t}) ; \mathrm{x} \in \mathbb{R}, \mathrm{t} \leqslant \mathrm{T}\}$ with boundary condition prescribed at $\mathrm{t}=\mathrm{T}$. Indeed, the finite difference method comes down to approximating the solution $\mathrm{u}(\cdot, \cdot)$ with a discrete assignment of the form

$$
(\mathrm{i} h, \mathrm{~T}-\mathrm{j} \Delta) \longrightarrow \mathrm{u}_{\mathrm{i}, \mathrm{j}}, \quad-\mathrm{m} \leqslant \mathrm{i} \leqslant \mathrm{m}, 0 \leqslant \mathrm{j} \leqslant \mathrm{n},
$$

for some sufficiently small time-step $\Delta>0$ and space-step $h>0$, where, given $\mathrm{j} \geqslant 0$, the list $u_{., j}$ is computed as a linear function of the list $u_{., j-1}$. Clearly, this analogy is based on the fact that the variable y in equation (3.1) can be interpreted as "time," as explained earlier. This is not a coincidence. In general, the notion of time is a reference to some - once and for all fixed - observable process chosen to be "the clock," and, as we now know, there is no universal choice of a clock which is intrinsic for all observ: able phenomena; in other words, time can only be relative. Equation (3.1) allows us to interpret the firm's accumulated earnings as being the intrinsic - one may call it "the financial" - clock in our setting. This should not come as a surprise: in order to price a stock option, one must look at the calendar and determine the time left to maturity, but when pricing the firm one must look at the available investment capital and deter: mine how many units of money - not units of time - remain to be collected before the option to invest can be exercised. The "financial clock" just described has some pecu: liar features which - science fiction aside - the usual calendar clock does not have. For example, liquidity can be understood as the ability to jump into the future relative to the financial clock. Another peculiarity is that the financial clock runs at a different speed at different points in the time-space; indeed, the coefficient $\pi(\mathrm{x})+\mathrm{ry}$ in equa: tion (3.1) is nothing but the rate at which the firm's accumulated earnings grow which is to say, the rate at which the financial clock is ticking - when the financial universe is in state $x$ and the financial clock is in state $y$. This explains why the method for solving the pricing equation (3.1) which is described in this section is more robust than the finite difference method - notice that the time-step in (3.10) depends on both 
$\mathrm{x}_{\mathrm{i}}$ and $\mathrm{y}_{\mathrm{j}-1}$. The finite difference method works well for parabolic equations in which, if not constant, the coefficients are at least time-invariant and, although on principle this method can be used to solve parabolic equations with time-dependent coefficients, typically, in this later case one is forced to work with an extremely small time step which, except for some rather special cases, renders the procedure intractable. In addition, as we will show below, the solution to $(3.1), \mathrm{V}(\cdot, \cdot)$, which satisfies the bud: get condition and the termination condition, is such that the derivative $\mathrm{V}^{(0,1)}(\cdot, \cdot)$ has a discontinuity at the point $(\mathrm{x}, \mathrm{y})=\left(\mathrm{x}^{*}, \mathcal{I}\right)$. Unlike the finite difference method, the procedure described in this section is quite robust when pathologies of this type hap: pen to occur. It should be noted also that while the finite difference method mimics the way in which partial derivatives are calculated, the procedure encoded in (3.10) mim: ics the way in which financial decisions are made; in fact, it mimics the very procedure from which the fundamental pricing equation derives. Consequently, this later method is better suited for problems involving dynamic programming, as is the case with the study of the optimal equity financing presented in $§ 5$ below.

Now we will present the output from the procedure encoded in (3.10) with the following data:

$$
\sigma=0.03, \mathrm{r}=0.05, \delta=0.07, c=2.0, I=11 .
$$

We will consider separately the tax-free case $\theta=0$ and the case $\theta=0.3$, which corre: sponds to a corporate tax of $30 \%$ on any income from the firm. With this choice for the parameters in the model, the critical threshold for the output price that triggers new investment is $\mathrm{x}^{*} \approx 4.96857$ when $\theta=0$ and $\mathrm{x}_{0.3}^{*} \approx 5.80917$ when $\theta=0.3$. We will approximate the solution in the rectangular region

$$
0 \leqslant \mathrm{x} \leqslant 10,0.0742101 \approx(1+\mathrm{r} * \mathrm{~d})^{-10000} \leqslant \mathrm{y} \leqslant 11, \text { whered }=0.01,
$$

by using the following grid when $\theta=0$ :

$$
\begin{gathered}
x_{i}=i \frac{1.48}{24}, \text { for } i=0, \ldots, 24, \\
x_{i}=1.5+(i-25) \frac{2.5-1.5}{59}, \text { for } i=25, \ldots, 84, \\
x_{i}=2.51+(i-85) \frac{4.3-2.51}{29}, \text { for } i=85, \ldots, 114, \\
x_{i}=4.31+(i-115) \frac{x^{*}-0.01-4.31}{19}, \text { for } i=115, \ldots, 134, \\
x_{i}=x^{*}+(i-135) \frac{5.7-x^{*}}{19}, \text { for } i=135, \ldots, 154, \\
x_{i}=5.8+(i-155) \frac{10.1-5.8}{39}, \text { for } i=155, \ldots, 194, \\
y_{j}=(1+r * d)^{-j} \times I, \text { for } j=0,1, \ldots, 10000 .
\end{gathered}
$$

With $\theta=0.3$ the following grid will be used:

$$
\begin{gathered}
x_{i}=i \frac{1.48}{24}, \text { for } i=0, \ldots, 24, \\
x_{i}=1.5+(i-25) \frac{2.5-1.5}{59}, \text { for } i=25, \ldots, 84,
\end{gathered}
$$




$$
\begin{gathered}
x_{i}=2.51+(i-85) \frac{5.2-2.51}{44}, \text { for } i=85, \ldots, 129, \\
x_{i}=5.21+(i-130) \frac{x_{0.3}^{*}-0.01-5.21}{19}, \text { for } i=130, \ldots, 149, \\
x_{i}=x_{0.3}^{*}+(i-150) \frac{6.4-x_{0.3}^{*}}{19}, \text { for } i=150, \ldots, 169, \\
x_{i}=6.5+(i-170) \frac{10.1-6.5}{34}, \text { for } i=170, \ldots, 204, \\
x_{i}=12+(i-205) \frac{20-12}{4}, \text { for } i=205, \ldots, 209, \\
y_{j}=(1+r * d)^{-j} \times I, \text { for } j=0,1, \ldots, 10000 .
\end{gathered}
$$

We have chosen to use a non-uniform grid in the variable $\mathrm{x}$ simply because this increases the efficiency in the procedure - one needs fewer interpolation nodes in regions that are further away from the singularities in the solution which occur at the critical values $\mathrm{x}=c$ and $\mathrm{x}=\mathrm{x}_{\theta}^{*}$. In the rest of this section we will present several 3D and contour plots of the function $(\mathrm{x}, \mathrm{y}) \longrightarrow \tilde{\mathrm{V}}(\mathrm{x}, \mathrm{y})$, constructed by way of polynomial interpolation from the assignment $\left(\mathrm{x}_{\mathrm{i}}, \mathrm{y}_{\mathrm{j}}\right) \longrightarrow \mathrm{v}_{\mathrm{i}, \mathrm{j}}$, where the values $\mathrm{v}_{\mathrm{i}, \mathrm{j}}$ are calculated according to the recursive rûle (3.10) from the boundary condition (3.9) with $\theta=0$ or $\theta=0.3$. Of course, we must somehow gauge how accurately the interpolation object $\tilde{\mathrm{V}}(\cdot, \cdot)$ approximates the actual solution $\mathrm{V}(\cdot, \cdot)$. Fortunately, although an accurate estimate of the rate of convergence to the actual solution when the size of the grid converges to 0 is difficult to obtain, on modern computing systems objects defined by way of polynomial interpolation can be manipulated (differentiated, integrated, plot: ted, etc) as ordinary functions. This allows us to interpret the symbols $\tilde{V}^{(2,0)}, \tilde{V}^{(1,0)}$ and $\tilde{\mathrm{V}}^{(0,1)}$ as well defined functions and, consequently, from the point of view of the comput: ing system, the assignment

$$
\begin{aligned}
(\mathrm{x}, \mathrm{y}) \longrightarrow \epsilon(\mathrm{x}, \mathrm{y}):=\frac{1}{2} \sigma^{2} \mathrm{x}^{2} \tilde{\mathrm{V}}^{(2,0)}(\mathrm{x}, \mathrm{y})+(\mathrm{r}-\delta) \mathrm{x} \tilde{\mathrm{V}}^{(1,0)}(\mathrm{x}, \mathrm{y}) \\
+(\pi(\mathrm{x})+\mathrm{ry}) \tilde{\mathrm{V}}^{(0,1)}(\mathrm{x}, \mathrm{y})-\mathrm{r} \tilde{\mathrm{V}}(\mathrm{x}, \mathrm{y})
\end{aligned}
$$

is a well defined function and the quantity

$$
\mathrm{e}=\max \left\{|\epsilon(\mathrm{x}, \mathrm{y})| ; \mathrm{x}_{0} \leqslant \mathrm{x} \leqslant \mathrm{x}_{\mathrm{m}}, \mathrm{y}_{0} \leqslant \mathrm{y} \leqslant \mathrm{y}_{\mathrm{n}}\right\}
$$

is a well defined positive real number. Clearly, this last quantity can be used as a mea: sure of how far from solving (3.1) in the rectangle $\llbracket \mathrm{x}_{0}, \mathrm{x}_{\mathrm{m}}, \rrbracket \times \llbracket \mathrm{y}_{0}, \mathrm{y}_{\mathrm{n}} \rrbracket$ the object $\tilde{\mathrm{V}}$ actually is. As the following graph shows, in the case $\theta=0$ one has $-0.01 \leqslant \epsilon \leqslant 0.01$ everywhere in the region

$$
\left\{(\mathrm{x}, \mathrm{y}) ; \mathrm{x}_{0} \leqslant \mathrm{x} \leqslant \mathrm{x}_{\mathrm{m}}, \mathrm{y}_{0} \leqslant \mathrm{y} \leqslant \mathrm{y}_{\mathrm{n}}\right\}
$$

except in a small neighborhood around the point $\left(\mathrm{x}_{\theta}^{*}, \mathcal{I}\right)$ and along the line $\mathrm{x}=c$. In fact, the spikes in the graph of the function $\epsilon$ around the point $\left(\mathrm{x}_{\theta}^{*}, \mathcal{I}\right)$ and the line $\mathrm{x}=c$ are mainly due to the inaccuracy in the representation of the derivative $\tilde{\mathrm{V}}^{(2,0)}$, not in the approximation $\tilde{V}$ of the actual solution, in those areas. This should be expected, since the second derivative of the function $\mathrm{x} \rightarrow \mathrm{g}_{\theta}(\mathrm{x})+\mathrm{q}_{\theta}(\mathrm{x})$ and the first derivative of the function $\mathrm{x} \longrightarrow \pi(\mathrm{x})$ have discontinuities, respectively, at $\mathrm{x}=\mathrm{x}_{\theta}^{*}$ and $\mathrm{x}=c$. It is possible to approximate the derivatives $\mathrm{V}^{(2,0)}$ and $\mathrm{V}^{(1,0)}$ in the same way in which the solution $\mathrm{V}$ was approximated and then force the interpolation procedure 
based on the assignment $\left(\mathrm{x}_{\mathrm{i}}, \mathrm{y}_{\mathrm{j}}\right) \longrightarrow \mathrm{v}_{\mathrm{i}, \mathrm{j}}$ to take into account information about the derivatives at each node - we will not pursue this higher level of precision since it is not really needed for our purpose.

$$
\text { (g1.jpg) }
$$

Fig. 1: The error function $\epsilon$ shown in the case $\theta=0$.

We will not display the error function in any of the remaining cases studied in this paper.

$$
\text { (g2.jpg) }
$$

Fig. 2: The value of an illiquid firm with an option to expand when $\theta=0$.

$$
\text { (g3.jpg) }
$$

Fig. 3: The value of an illiquid firm with an option to expand when $\theta=0$.

$$
\text { (g4.jpg) }
$$

Fig. 4: The MRSRE for an illiquid firm with an option to expand when $\theta=0$.

$$
\text { (g5.jpg) }
$$

Fig. 5: The MRSRE for an illiquid firm with an option to expand when $\theta=0$.

The discontinuity in the MRSRE exhibited in the last plot can be verified analytically. In fact, the one sided derivative

$$
\lim _{\mathrm{y}>I} \frac{\mathrm{V}(\mathrm{x}, \mathcal{I})-\mathrm{V}(\mathrm{x}, \mathrm{y})}{I-\mathrm{y}}
$$

can be computed in closed form for all $\mathrm{x}>0$ as follows. Set

$$
\mathrm{y} \equiv \mathrm{y}(\mathrm{t})=\frac{I-\mathrm{t} \pi(\mathrm{x})}{\mathrm{r} \mathrm{t}+1} \Longleftrightarrow(\pi(\mathrm{x})+\mathrm{r} \mathrm{y}) \times \mathrm{t}=\mathcal{I}-\mathrm{y}
$$

and suppose that $\mathrm{x} \geqslant \mathrm{x}^{*}$. Under this assumption one has

$$
\lim _{\mathrm{y}>I} \frac{\mathrm{V}(\mathrm{x}, I)-\mathrm{V}(\mathrm{x}, \mathrm{y})}{I-\mathrm{y}}=\lim _{\mathrm{t} \backslash 0} 2 \frac{\mathrm{g}(\mathrm{x})-e^{-\mathrm{rt}} \mathrm{E}\left[\mathrm{g}\left(\mathcal{E}_{\mathrm{t}}^{\mathrm{x}}\right)\right]}{(\pi(\mathrm{x})+\mathrm{ry}(\mathrm{t})) \times \mathrm{t}},
$$

where

$$
\mathcal{E}_{\mathrm{t}}^{\mathrm{X}}=\mathrm{X} e^{\sigma \beta_{\mathrm{t}}+\left(\mathrm{r}-\delta-\frac{1}{2} \sigma^{2}\right) \mathrm{t}}
$$

By Itô's formula,

$$
\begin{aligned}
e^{-\mathrm{rt}} \mathrm{g}\left(\mathcal{E}_{\mathrm{t}}^{\mathrm{x}}\right)-\mathrm{g}(\mathrm{x})=\int_{0}^{\mathrm{t}} e^{-\mathrm{rs}}\left(-\mathrm{rg}\left(\mathcal{E}_{\mathrm{s}}^{\mathrm{x}}\right)+\right. & \left.(\mathrm{r}-\delta) \mathrm{g}^{\prime}\left(\mathcal{E}_{\mathrm{s}}^{\mathrm{x}}\right)+\frac{\sigma^{2}}{2} \mathrm{~g}^{\prime \prime}\left(\mathcal{E}_{\mathrm{s}}^{\mathrm{X}}\right)\right) d \mathrm{~s} \\
& +\sigma \int_{0}^{\mathrm{t}} e^{-\mathrm{rs}} \mathrm{g}^{\prime}\left(\mathcal{E}_{\mathrm{s}}^{\mathrm{x}}\right) d \aleph_{\mathrm{s}},
\end{aligned}
$$

and since the valuation map $\mathrm{g}(\cdot)$ satisfies the equation

$$
\frac{1}{2} \sigma^{2} \mathrm{~g}^{\prime \prime}(\mathrm{x})+(\mathrm{r}-\delta) \mathrm{g}^{\prime}(\mathrm{x})+\pi(\mathrm{x})=\mathrm{rg}(\mathrm{x}),
$$

it follows that

$$
\mathrm{E}\left[\mathrm{g}(\mathrm{x})-e^{-\mathrm{rt}} \mathrm{g}\left(\mathcal{E}_{\mathrm{t}}^{\mathrm{x}}\right)\right]=\int_{0}^{\mathrm{t}} e^{-\mathrm{rs}} \pi\left(\mathcal{E}_{\mathrm{s}}^{\mathrm{x}}\right) d \mathrm{~s},
$$

from where one finds that 


$$
\lim _{\mathrm{y} \lambda I} \frac{\mathrm{V}(\mathrm{x}, \mathcal{I})-\mathrm{V}(\mathrm{x}, \mathrm{y})}{I-\mathrm{y}}=2 \lim _{\mathrm{t} \backslash 0} \frac{\frac{1}{\mathrm{t}} \int_{0}^{\mathrm{t}} e^{-\mathrm{rs}} \pi\left(\mathcal{E}_{\mathrm{s}}^{\mathrm{x}}\right) d \mathrm{~s}}{\pi(\mathrm{x})+\mathrm{ry}(\mathrm{t})}=\frac{2 \pi(\mathrm{x})}{\pi(\mathrm{x})+\mathrm{r} \mathcal{I}} .
$$

Similarly, when $\mathrm{x}<\mathrm{x}^{*}$ one has

$$
\lim _{\mathrm{y}>I} \frac{\mathrm{V}(\mathrm{x}, \mathcal{I})-\mathrm{V}(\mathrm{x}, \mathrm{y})}{I-\mathrm{y}}=\lim _{\mathrm{t} \backslash 0} \frac{\mathrm{q}(\mathrm{x})+\mathrm{g}(\mathrm{x})-e^{-\mathrm{rt}} \mathrm{E}\left[\mathrm{q}\left(\mathcal{E}_{\mathrm{t}}^{\mathrm{x}}\right)+\mathrm{g}\left(\mathcal{E}_{\mathrm{t}}^{\mathrm{x}}\right)\right]}{(\pi(\mathrm{x})+\mathrm{ry}(\mathrm{t})) \times \mathrm{t}},
$$

and, after taking into account that the valuation map $\mathrm{q}(\cdot)$ satisfies the equation

$$
\frac{1}{2} \sigma^{2} \mathrm{q}^{\prime \prime}(\mathrm{x})+(\mathrm{r}-\delta) \mathrm{q}^{\prime}(\mathrm{x})=\mathrm{rq}(\mathrm{x})
$$

one finds that

$$
\lim _{\mathrm{y}>I} \frac{\mathrm{V}(\mathrm{x}, \mathcal{I})-\mathrm{V}(\mathrm{x}, \mathrm{y})}{I-\mathrm{y}}=\lim _{\mathrm{t} \backslash 0} \frac{\frac{1}{\mathrm{t}} \int_{0}^{\mathrm{t}} e^{-\mathrm{rs}} \pi\left(\mathcal{E}_{\mathrm{s}}^{\mathrm{x}}\right) d \mathrm{~s}}{\pi(\mathrm{x})+\mathrm{ry}(\mathrm{t})}=\frac{\pi(\mathrm{x})}{\pi(\mathrm{x})+\mathrm{r} \mathcal{I}},
$$

which explains the jump

$$
\mu\left(\mathrm{x}^{*}+, \mathcal{I}\right)-\mu\left(\mathrm{x}^{*}-, \mathcal{I}\right)=\frac{\pi\left(\mathrm{x}^{*}\right)}{\pi\left(\mathrm{x}^{*}\right)+\mathrm{r} \mathcal{I}},
$$

where $\mu(\mathrm{x}, \mathcal{I}):=\lim _{\mathrm{y} \lambda I} \mu(\mathrm{x}, \mathrm{y})$.

Now we will consider the case where all income from the firm is subject to $30 \%$ corporate tax - this corresponds to setting $\theta=0.3$.

$$
\text { (g6.jpg) }
$$

Fig. 6: The value of an illiquid firm with an option to expand when $\theta=0.3$.

$$
\text { (g7.jpg) }
$$

Fig. 7: The value of an illiquid firm with an option to expand when $\theta=0.3$.

$$
\text { (g8.jpg) }
$$

Fig. 8: The MRSRE for an illiquid firm with an option to expand when $\theta=0.3$.

$$
\text { (99.jpg) }
$$

Fig. 9: The MRSRE for an illiquid firm with an option to expand when $\theta=0.3$.

The last plot shows something quite intuitive: when the output price $\mathrm{x}$ is in the range $\rrbracket c, x_{\theta}^{*} \llbracket$ and the level of retained earnings $\mathrm{y}$ is very close to the investment cost $I$, the MRSRE is strictly less than 1 , since in this case part of any cash added to the firm's bank account is lost to taxes. However, this does not happen when $\mathrm{x}<\boldsymbol{c}$, since in this case the firm does not produce and therefore there is nothing to push the retained earnings above the level $\mathcal{I}$, which would then force the firm to distribute some of its cash as dividends and therefore give away part of it in the form of taxes. Of course, if the level of retained earnings y is very close to, but still strictly less than, the amount $\mathcal{I}$ and a large sum of money is added to the firm's bank account, almost 30\% of this sum will be lost to taxes, since, as a result of this infusion of cash, the firm's retained earnings will exceed the investment cost $I$ regardless of whether the firm is producing or not. This observation should not be seen as a contradiction to the plot shown on Fig. 9. Indeed, the MRSRE is a relation between infinitesimal quantities only; namely, it is the ratio between the infinitesimal improvement in the value of the firm as a result of adding an infinitesimal amount of money to its bank account.

Clearly, when the MRSRE is strictly larger than 1, taking $\varepsilon$ units of money out of the firm decreases the value of the firm by more than $\varepsilon$ units of money. In particu: 
lar, Fig. 5 shows that in a tax-free economy the owners of an illiquid firm with an option to expand will decrease their wealth if they collect dividends while the level of retained earnings is strictly smaller than the cost of new investment. It is interesting that, even though the MRSRE happens to be smaller than 1 for certain choices of $\mathrm{x}$ and $y$ when taxes are taken into account, as the plots in Fig. 8 and Fig. 9 show, paying dividends before the level of retained earnings has reached the cost of new investment is still prohibitive. This is because the MRSRE is strictly larger than $1-\theta=0.7$ in the entire region and this means that taking $\varepsilon$ units of money out of the firm decreases the firm's value by more than $0.7 \varepsilon$ units of money, while, after paying $30 \%$ tax, what is left from the $\varepsilon$ units of money taken out is exactly $0.7 \varepsilon$ units of money - plainly, the harm from taking $\varepsilon$ units of money out of the firm still outweighs the benefit. Later we will show that only in an economy without frictions of any kind - i.e., only in the case of a publicly traded firm, no taxes and no transaction costs - the act of paying divi: dends when the level of retained earnings is still smaller than the cost of new invest: ment happens not to harm — not to affect, in fact — the shareholders' wealth, as pre: scribed by the Modigliani-Miller theory.

Of course, when the MRSRE is strictly larger than 1, adding $\varepsilon$ units of money to the firm's bank account increases - instantly — the value of the firm by more than $\varepsilon$ units of money. One must realize that such "instant money making opportunities" are available to the owners of the firm only and do not represent arbitrage of any kind, for, the ability to spend $\varepsilon$ units of money and receive in exchange a financial entity worth more that $\varepsilon$ units of money is simply a payoff to the shareholders for their investment in the firm. One way or another, any opportunity to instantly increase one's wealth would be quickly seized by the financial markets, which is to say that the model devel: oped in this section should be seen mainly as a model of the factors that actually force the shareholders to sell new equity in the firm. As we will see in the next section, unless the MRSRE for an illiquid firm is strictly larger than 1 in certain states of the economy, it would be difficult to explain why the owners of the firm with an option to expand are willing — not merely indifferent — to sell new equity in the firm.

\section{§4. The Effect of Equity Financing on the Shareholders' Wealth}

Consider again the illiquid firm with an option to expand that was discussed in the previous section and let $\mathcal{R} \ni(\mathrm{x}, \mathrm{y}) \longrightarrow \mathrm{V}(\mathrm{x}, \mathrm{y})$ be the valuation map determined by the fundamental pricing equation (3.1), in conjunction with the budget condition (1.11) and the termination condition (1.10), so that $\mathrm{V}\left(\mathrm{X}_{\mathrm{t}}, \mathrm{Y}_{\mathrm{t}}\right)$ gives the value of the illiquid firm with an option to expand at time $t \geqslant 0$. In our setting, the fact that the firm becomes liquid simply means that the owners are allowed to sell new equity, i.e., some form of equity financing becomes available. For the sake of simplicity, we will treat liquidity as an instantaneous event, i.e., once new equity is issued and sold — which we assume happens instantly — the firm becomes illiquid again. Thus, claiming that the firm is illiquid does not necessarily mean that shares of common stock in the firm are not traded - it just means that the firm does not issue and sell new shares of common stock. This interpretation of the term «liquid» is consistent with the view that the firm can be treated as a contingent claim, which, whether traded or not, has market value determined solely by the output price $X_{t}$ and the level of retained earnings $Y_{t}$. In this context, liquidity is nothing but the firm's ability to switch — instantly - from owning a financial entity worth $\mathrm{V}\left(\mathrm{X}_{\mathrm{t}}, \mathrm{Y}_{\mathrm{t}}\right)$ units of money to owning $\mathrm{p} \times 100 \%$ equity in a financial entity worth $\mathrm{V}\left(\mathrm{X}_{\mathrm{t}}, \mathrm{Y}_{\mathrm{t}}+\Delta\right)$ units of money, for some choice of $\Delta>0$ and 
$\mathrm{p} \in \rrbracket 0,1[$. This is very similar to assuming that, regardless of whether it is traded or not, the present value of a stock option on the output price $X_{t}, t \geqslant 0$, can be expressed as $\mathrm{u}\left(\mathrm{X}_{\mathrm{t}}, \mathrm{t}\right)$, where the valuation map $\mathrm{u}(\cdot, \cdot)$ is determined by the standard Black-Sc: holes equation from the appropriate boundary conditions. In fact, apart from the technical differences between the fundamental pricing equation (3.1) and the standard Black-Scholes equation, the only difference between our treatment of the firm and the usual treatment of american stock options with infinite maturity is that the holder of a stock option cannot, so to speak, leap into the future - see 3:5 - and switch from owning a financial instrument worth $\mathrm{u}\left(\mathrm{X}_{\mathrm{t}}, \mathrm{t}\right)$ units of money to owning a financial instrument worth $\mathrm{p} \times \mathrm{u}\left(\mathrm{X}_{\mathrm{t}}, \mathrm{t}+\Delta\right)$ units of money, for some $\Delta>0$ and some $\mathrm{p} \in$ 『0, 1[. Our main goal in this section is to investigate the way in which liquidity, i.e., the availability of various forms of equity financing, affect the share price and the shareholders wealth.

In general, equity financing can be viewed as a method for creating a financial entity worth $\mathrm{V}\left(\mathrm{X}_{\mathrm{t}}, \mathrm{Y}_{\mathrm{t}}+\Delta\right)$ units of money by combining a financial entity worth $\mathrm{V}\left(\mathrm{X}_{\mathrm{t}}, \mathrm{Y}_{\mathrm{t}}\right)$ units of money, which is owned by the present, i.e., the acting, shareholders, with a financial entity worth $\Delta$ units of money, which is simply the cash owned by the investors, i.e., the new shareholders. The newly-created financial entity is then owned jointly by the owners of the two financial entities from which it was derived. Suppose that after this transaction the acting shareholders own $\mathrm{p} \times 100 \%$ equity in the firm, while the new shareholders own the remaining $(1-p) \times 100 \%$ of the equity, for some $p \in \rrbracket 0,1[$. The acting shareholders would be willing to enter the contract only if

$$
\mathrm{p} \times \mathrm{V}\left(\mathrm{X}_{\mathrm{t}}, \mathrm{Y}_{\mathrm{t}}+\Delta\right) \geqslant \mathrm{V}\left(\mathrm{X}_{\mathrm{t}}, \mathrm{Y}_{\mathrm{t}}\right) \text {, }
$$

while the new shareholders would be willing to enter the contract only if

$$
(1-\mathrm{p}) \times \mathrm{V}\left(\mathrm{X}_{\mathrm{t}}, \mathrm{Y}_{\mathrm{t}}+\Delta\right) \geqslant(1+\vartheta) \Delta,
$$

where $\vartheta \times 100 \% \geqslant 0$ is the fixed percentage of the total payment to the original share: holders that the new shareholders must pay to the broker in the form of transaction fee. But how is the proportion of ownership $p \in \rrbracket 0,1[$ determined in this transac: tion? To gain some insight into the nature of this question, notice that when the above two conditions are satisfied, the transaction that we just described leads to the creation of new wealth worth

$$
\mathrm{V}\left(\mathrm{X}_{\mathrm{t}}, \mathrm{Y}_{\mathrm{t}}+\Delta\right)-\mathrm{V}\left(\mathrm{X}_{\mathrm{t}}, \mathrm{Y}_{\mathrm{t}}\right)-(1+\vartheta) \Delta
$$

units of money. Consequently, the question that we just asked essentially comes down to asking: How is this new wealth distributed among the owners of the two financial entities from which it was derived? In order to keep the model as simple as possible and avoid the use of game theory or auctions theory, we will simply postulate that when shares of common stock in the firm are traded at auction, the newly-created wealth is taken entirely by the acting shareholders, which is equivalent to

$$
(1-\mathrm{p}) \times \mathrm{V}\left(\mathrm{X}_{\mathrm{t}}, \mathrm{Y}_{\mathrm{t}}+\Delta\right)=(1+\vartheta) \Delta \Longleftrightarrow \frac{\mathrm{V}\left(\mathrm{X}_{\mathrm{t}}, \mathrm{Y}_{\mathrm{t}}+\Delta\right)-(1+\vartheta) \Delta}{\mathrm{V}\left(\mathrm{X}_{\mathrm{t}}, \mathrm{Y}_{\mathrm{t}}+\Delta\right)}=\mathrm{p} .
$$

The reason for this assumption is that in the presence of an infinite number of bidders, one should not be able to purchase at auction a financial instrument worth $(1-\mathrm{p}) \times \mathrm{V}\left(\mathrm{X}_{\mathrm{t}}, \mathrm{Y}_{\mathrm{t}}+\Delta\right)$ units of money by spending less than $(1-\mathrm{p}) \times \mathrm{V}\left(\mathrm{X}_{\mathrm{t}}, \mathrm{Y}_{\mathrm{t}}+\Delta\right)$ units of money; in other words, (4.2) simply describes a state of equilibrium in the market for equity in the firm. 
Next, suppose that there are $\mathrm{N} \geqslant 1$ shares outstanding and that the expression in (4.1) is strictly positive. Should it be possible to auction new shares of equity in the firm, the owners, i.e., the acting shareholders, can increase the value of the equity that they own from something worth $\mathrm{V}\left(\mathrm{X}_{\mathrm{t}}, \mathrm{Y}_{\mathrm{t}}\right)$ units of money to something worth $\mathrm{V}\left(\mathrm{X}_{\mathrm{t}}, \mathrm{Y}_{\mathrm{t}}+\Delta\right)-(1+\vartheta) \Delta$ units of money. If one is to assume that the owners are ratio: nal and that there is no asymmetry of information, i.e., all agents are aware that the firm can auction new equity, the price at which the firm's shares of common stock including old and new shares - will be traded is

$$
\mathrm{S}_{0}=\frac{\mathrm{V}\left(\mathrm{X}_{\mathrm{t}}, \mathrm{Y}_{\mathrm{t}}+\Delta\right)-(1+\vartheta) \Delta}{\mathrm{N}}
$$

(since the newly issued shares are identical to the existing ones, they must sell at the same price). Consequently, in order to raise $\Delta$ units of money the firm will have to issue and sell at auction $v=\frac{\Delta}{\mathrm{S}_{0}}$ new shares. Of course, the owners of the firm would choose $\Delta$ in such a way that, given the current state $\left(\mathrm{X}_{\mathrm{t}}, \mathrm{Y}_{\mathrm{t}}\right)$, the share price $\mathrm{S}_{0}$ would be as big as possible. However, since the firm must distribute as dividends any cash in excess of the amount $\mathcal{I}$, there will be no advantage of choosing $\Delta$ in such a way that $\mathrm{Y}_{\mathrm{t}}+\Delta>I$, even if the firm's profits are exempt from taxes and there are no transac: tion costs. Indeed, one can assume that without taxes any cash in the firm in excess of the amount $\mathcal{I}$, being immediately paid out, is simply worth what its cash value is, which means that when $\Delta=\left(I-\mathrm{Y}_{\mathrm{t}}\right)+\varepsilon$ for some $\varepsilon>0$ one must have

$$
\mathrm{V}\left(\mathrm{X}_{\mathrm{t}}, \mathrm{Y}_{\mathrm{t}}+\Delta\right) \equiv \mathrm{V}\left(\mathrm{X}_{\mathrm{t}}, \mathcal{I}+\varepsilon\right)=\mathrm{V}\left(\mathrm{X}_{\mathrm{t}}, \mathcal{I}\right)+\varepsilon,
$$

and, as a result,

$$
\mathrm{V}\left(\mathrm{X}_{\mathrm{t}}, \mathrm{Y}_{\mathrm{t}}+\Delta\right)-\Delta \equiv \mathrm{V}\left(\mathrm{X}_{\mathrm{t}}, \mathcal{I}\right)+\varepsilon-\left(\mathcal{I}-\mathrm{Y}_{\mathrm{t}}\right)-\varepsilon=\mathrm{V}\left(\mathrm{X}_{\mathrm{t}}, \mathcal{I}\right)-\left(\mathcal{I}-\mathrm{Y}_{\mathrm{t}}\right) .
$$

For the sake of simplicity, we will suppose that if at time $t \geqslant 0$ the firm decides to increase the amount of cash that it owns by way of selling new equity, the amount of cash that can be raised always equals $\Delta=I-Y_{t}$, which is the minimal amount the firm must collect in order to bring its cash reserve to the level required by the expan: sion project. Consequently, the price at which the new shares can be sold at auction is given by

$$
\mathrm{S}_{0}=\frac{\mathrm{V}\left(\mathrm{X}_{\mathrm{t}}, \mathcal{I}\right)-(1+\vartheta) \times\left(\mathcal{I}-\mathrm{Y}_{\mathrm{t}}\right)}{\mathrm{N}} .
$$

Notice that this choice for $\Delta$ is optimal, in the sense that $S_{0}$ is maximal, if the following property holds: $\mu\left(X_{t}, y\right) \geqslant(1+\vartheta)$ whenever $\mathrm{Y}_{\mathrm{t}} \leqslant \mathrm{y} \leqslant \mathcal{I}$. In particular, choosing $\Delta=$ $I-Y_{t}$ is optimal in regions where the MRSRE is greater than 1 and the purchase of new shares involves no transaction costs. Thus, the type of liquidity that we have just discussed, which we will call public trading, essentially means that at time $t \geqslant 0$ the owners of the firm can choose between owning a financial entity worth $V\left(X_{t}, Y_{t}\right)$ units of money and owning a financial entity worth

$$
\mathrm{V}\left(\mathrm{X}_{\mathrm{t}}, \mathcal{I}\right)-(1+\vartheta) \times\left(\mathcal{I}-\mathrm{Y}_{\mathrm{t}}\right)
$$

units of money. As a result of this observation, when public trading is available to the owners of the firm and the following condition holds

$$
\mathrm{V}\left(\mathrm{X}_{\mathrm{t}}, \mathcal{I}\right)-(1+\vartheta) \times\left(\mathcal{I}-\mathrm{Y}_{\mathrm{t}}\right)>\mathrm{V}\left(\mathrm{X}_{\mathrm{t}}, \mathrm{Y}_{\mathrm{t}}\right)
$$

by choosing to become liquid and raise $\Delta=I-Y_{\mathrm{t}}$ units of money by way of public trading, the acting shareholders actually increase the value of the equity that they own by $f_{0} \times 100 \%$, where 


$$
f_{0}=\frac{\mathrm{V}\left(\mathrm{X}_{\mathrm{t}}, \mathcal{I}\right)-\mathrm{V}\left(\mathrm{X}_{\mathrm{t}}, \mathrm{Y}_{\mathrm{t}}\right)-(1+\vartheta) \times\left(\mathcal{I}-\mathrm{Y}_{\mathrm{t}}\right)}{\mathrm{V}\left(\mathrm{X}_{\mathrm{t}}, \mathrm{Y}_{\mathrm{t}}\right)} .
$$

Assuming that the shareholders are rational, they would issue new equity only when $\epsilon_{0}>0$ and when $f_{0}=0$ they would be indifferent between selling new equity or taking no action. We will assume that unless they have a reason to do so, the shareholders would not sell new equity. Notice that $\mu\left(\mathrm{X}_{\mathrm{t}}, \mathrm{y}\right) \equiv \mathrm{V}^{(0,1)}\left(\mathrm{X}_{\mathrm{t}}, \mathrm{y}\right) \geqslant 1+\vartheta$ for $\mathrm{Y}_{\mathrm{t}} \leqslant \mathrm{y} \leqslant \mathcal{I}$ implies that $f_{0} \geqslant 0$ and that $\mu\left(\mathrm{X}_{\mathrm{t}}, \mathrm{y}\right)=1+\vartheta$ for $\mathrm{Y}_{\mathrm{t}} \leqslant \mathrm{y} \leqslant \mathcal{I}$ implies that $\epsilon_{0}=0$. Thus, when the MRSRE for an illiquid firm with an option to expand is identically equal to 1 one has $f_{0} \leqslant 0$ and the indifference condition $f_{0}=0$ holds only when $\theta=0$, i.e., only in the absence of transaction costs.

Now we will consider a different type of liquidity which we will call internal trading, meaning, trading without competition among many potential buyers. Sup: pose that for some reason the firm cannot sell equity at auction but is nevertheless willing to sell - and there is an agent who is willing to buy - equity in the firm in exchange for $\Delta$ units of money. After this transaction, the agent and the original owner of the firm will both own a financial entity worth $\mathrm{V}\left(\mathrm{X}_{\mathrm{t}}, \mathrm{Y}_{\mathrm{t}}+\Delta\right)$ units of money. So, how should this financial entity be split between the acting shareholders and the agent, i.e., between old and new shareholders? Of course, if the new equity in the firm is not sold at auction, one can no longer make the assumption that the original owners, i.e., the acting shareholders, capture the full value of the amount in (4.1), which represents the new wealth created as a result of adding $\Delta$ units of money to the firm's bank account. Once again, we choose to keep the model as simple as possible and postulate that the amount in (4.1) is split between old and new shareholders in the same ratio as the ratio between their respective endowments, which is $\mathrm{V}\left(\mathrm{X}_{\mathrm{t}}, \mathrm{Y}_{\mathrm{t}}\right) \div \Delta-$ as we will soon see, this choice simply encodes the fact that the contract is being negotiated between the sellers and the buyers. For the sake of simplicity, we will suppose that internal trading can be accomplished without a broker and therefore does not involve transaction costs of any kind. Thus, after the sale of the new equity, the equity owned by the acting shareholders, i.e., the original owners, will be worth

$$
\begin{aligned}
\mathrm{V}\left(\mathrm{X}_{\mathrm{t}}, \mathrm{Y}_{\mathrm{t}}\right)+\frac{\mathrm{V}\left(\mathrm{X}_{\mathrm{t}}, \mathrm{Y}_{\mathrm{t}}\right)}{\mathrm{V}\left(\mathrm{X}_{\mathrm{t}}, \mathrm{Y}_{\mathrm{t}}\right)+\Delta}\left(\mathrm{V}\left(\mathrm{X}_{\mathrm{t}}, \mathrm{Y}_{\mathrm{t}}+\Delta\right)\right. & \left.-\mathrm{V}\left(\mathrm{X}_{\mathrm{t}}, \mathrm{Y}_{\mathrm{t}}\right)-\Delta\right) \\
& =\frac{\mathrm{V}\left(\mathrm{X}_{\mathrm{t}}, \mathrm{Y}_{\mathrm{t}}+\Delta\right)}{\mathrm{V}\left(\mathrm{X}_{\mathrm{t}}, \mathrm{Y}_{\mathrm{t}}\right)+\Delta} \times \mathrm{V}\left(\mathrm{X}_{\mathrm{t}}, \mathrm{Y}_{\mathrm{t}}\right)
\end{aligned}
$$

units of money, while the equity owned by the new shareholders will be worth

$$
\Delta+\frac{\Delta}{\mathrm{V}\left(\mathrm{X}_{\mathrm{t}}, \mathrm{Y}_{\mathrm{t}}\right)+\Delta}\left(\mathrm{V}\left(\mathrm{X}_{\mathrm{t}}, \mathrm{Y}_{\mathrm{t}}+\Delta\right)-\mathrm{V}\left(\mathrm{X}_{\mathrm{t}}, \mathrm{Y}_{\mathrm{t}}\right)-\Delta\right)=\frac{\mathrm{V}\left(\mathrm{X}_{\mathrm{t}}, \mathrm{Y}_{\mathrm{t}}+\Delta\right)}{\mathrm{V}\left(\mathrm{X}_{\mathrm{t}}, \mathrm{Y}_{\mathrm{t}}\right)+\Delta} \times \Delta
$$

units of money. It is interesting that in this contract the percentage of increase in the value of the respective endowments of old and new shareholders is the same and equals $f_{*} \times 100 \%$ with

$$
f_{*}=\frac{\mathrm{V}\left(\mathrm{X}_{\mathrm{t}}, \mathrm{Y}_{\mathrm{t}}+\Delta\right)-\mathrm{V}\left(\mathrm{X}_{\mathrm{t}}, \mathrm{Y}_{\mathrm{t}}\right)-\Delta}{\mathrm{V}\left(\mathrm{X}_{\mathrm{t}}, \mathrm{Y}_{\mathrm{t}}\right)+\Delta} .
$$

This is exactly what one should expect in a contract which is negotiated between the seller and the buyer under the condition that neither side has any kind of leverage in the negotiation, which is what we implicitly assume. 
It turns out that internal trading is equivalent to having the original sharehold: ers issue and sell, in addition to the existing $\mathrm{N}$ shares outstanding, $v$ shares at the current price

$$
\mathrm{S}_{0}=\frac{1}{\mathrm{~N}} \mathrm{~V}\left(\mathrm{X}_{\mathrm{t}}, \mathrm{Y}_{\mathrm{t}}\right)
$$

which is simply the price per share for an illiquid firm. Indeed, if the amount of cash raised after $v$ additional shares are sold is $\Delta=v \mathrm{~S}_{0}$, the share price will change from $\mathrm{S}_{0}$ to

$$
\begin{array}{r}
\mathrm{S}_{1}=\frac{\mathrm{V}\left(\mathrm{X}_{\mathrm{t}}, \mathrm{Y}_{\mathrm{t}}+\Delta\right)}{\mathrm{N}+v}=\frac{\mathrm{V}\left(\mathrm{X}_{\mathrm{t}}, \mathrm{Y}_{\mathrm{t}}+\Delta\right)}{\mathrm{N}+\frac{\mathrm{N} \Delta}{\mathrm{V}\left(\mathrm{X}_{\mathrm{t}}, \mathrm{Y}_{\mathrm{t}}\right)}}=\frac{1}{\mathrm{~N}} \times \frac{\mathrm{V}\left(\mathrm{X}_{\mathrm{t}}, \mathrm{Y}_{\mathrm{t}}+\Delta\right)}{1+\frac{\Delta}{\mathrm{V}\left(\mathrm{X}_{\mathrm{t}}, \mathrm{Y}_{\mathrm{t}}\right)}} \\
=\frac{\mathrm{V}\left(\mathrm{X}_{\mathrm{t}}, \mathrm{Y}_{\mathrm{t}}\right)}{\mathrm{N}} \times \frac{\mathrm{V}\left(\mathrm{X}_{\mathrm{t}}, \mathrm{Y}_{\mathrm{t}}+\Delta\right)}{\mathrm{V}\left(\mathrm{X}_{\mathrm{t}}, \mathrm{Y}_{\mathrm{t}}\right)+\Delta},
\end{array}
$$

so that the quantity $\mathrm{N} \mathrm{S}_{1}$, which represents the value of the acting shareholders' equity after the transaction, coincides with the expression in (4.3). This observation is com: pletely consistent with the intuition: if the new shares are purchased by an agent who does not compete with other agents for investing in the firm and, at the same time, the acting shareholders do not compete with other shareholders for investment capital, the price that the firm can charge is simply the market price of an illiquid firm and, in general, without competing buyers and sellers, the firm's decision to sell new equity, i.e., to become liquid by way of internal trading, cannot change the share price. J ust as we did earlier, in this case, too, we suppose that the only feasible choice for $\Delta$ is $\Delta=\mathcal{I}-\mathrm{Y}_{\mathrm{t}}$, i.e., we suppose that the amount of cash raised always equals the amount needed to bring the firm's cash to the level required by the expansion project. Thus, by deciding to make the firm liquid in terms of internal trading, the acting shareholders increase the value of the equity that they own by $f_{1} \times 100 \%$, where

$$
f_{1}=\frac{\mathrm{V}\left(\mathrm{X}_{\mathrm{t}}, \mathcal{I}\right)-\mathrm{V}\left(\mathrm{X}_{\mathrm{t}}, \mathrm{Y}_{\mathrm{t}}\right)-\left(\mathcal{I}-\mathrm{Y}_{\mathrm{t}}\right)}{\mathrm{V}\left(\mathrm{X}_{\mathrm{t}}, \mathrm{Y}_{\mathrm{t}}\right)+\mathcal{I}-\mathrm{Y}_{\mathrm{t}}} .
$$

If one is to assume again that the acting shareholders are rational, they would issue and sell internally new equity only when $f_{1}>0$ and if $f_{1}=0$ they would be indifferent between entering the contract or doing nothing. Notice that $\mu\left(X_{t}, y\right) \equiv V^{(0,1)}\left(X_{t}, y\right) \geqslant 1$ for $\mathrm{Y}_{\mathrm{t}} \leqslant \mathrm{y} \leqslant \mathcal{I}$ implies that $\epsilon_{1} \geqslant 0$ and $\mu\left(\mathrm{X}_{\mathrm{t}}, \mathrm{y}\right)=1$ for $\mathrm{Y}_{\mathrm{t}} \leqslant \mathrm{y} \leqslant \mathcal{I}$ implies that $f_{1}=0$. Thus, in regions where the MRSRE for an illiquid firm with an option to expand is identically equal to 1 , one has $f_{1}=0$.

Next, we will consider the case of shareholders' buyout. With this type of equity financing, new shares are sold only to the existing shareholders; more specifi: cally, assuming that there are $\mathrm{N}$ shares outstanding, every shareholder is allowed to purchase $\frac{v}{N}$ additional shares for every share owned at the current price $\mathrm{S}_{0}=$ $\frac{1}{\mathrm{~N}} \mathrm{~V}\left(\mathrm{X}_{\mathrm{t}}, \mathrm{Y}_{\mathrm{t}}\right)$ for the total expense of $\frac{v}{\mathrm{~N}} \times \mathrm{S}_{0}=\frac{\Delta}{\mathrm{N}}$ units of money, where $\Delta$ is the total amount raised in the transaction. Thus, the shareholders buyout differs from the internal trading only in that the buyers are the existing shareholders. Just as in the case of internal trading, we will suppose that the shareholders buyout, too, does not require a broker and therefore does not involve transaction fees. Consequently, by choosing to raise $\Delta$ units of money by way of shareholders buyout of $v$ additional shares, the shareholders increase the value of each share of equity from $\frac{1}{N} V\left(X_{t}, Y_{t}\right)$ units of money to 


$$
\left(1+\frac{v}{\mathrm{~N}}\right) \frac{\mathrm{V}\left(\mathrm{X}_{\mathrm{t}}, \mathrm{Y}_{\mathrm{t}}+\Delta\right)}{\mathrm{N}+v}-\frac{\Delta}{\mathrm{N}}=\frac{\mathrm{V}\left(\mathrm{X}_{\mathrm{t}}, \mathrm{Y}_{\mathrm{t}}+\Delta\right)-\Delta}{\mathrm{N}}
$$

units of money. In other words, the shareholders buyout can be seen as an option to turn equity worth $\frac{1}{\mathrm{~N}} \mathrm{~V}\left(\mathrm{X}_{\mathrm{t}}, \mathrm{Y}_{\mathrm{t}}\right)$ units of money into equity worth $\left(1+\frac{v}{\mathrm{~N}}\right) \frac{\mathrm{V}\left(\mathrm{X}_{\mathrm{t}}, \mathrm{Y}_{\mathrm{t}}+\Delta\right)}{\mathrm{N}+v}$ units of money by spending $\frac{\Delta}{N}$ units of money. We will again assume that the amount raised in this transaction can only equal $\Delta=\mathcal{I}-\mathrm{Y}_{\mathrm{t}}$ units of money. Thus, if the share: holders are rational and there is no asymmetry of information, in the sense that all agents are aware that shareholders' buyout is available as an instrument, the market price of each share of common stock must equal

$$
\frac{1}{\mathrm{~N}} \operatorname{Max}\left[\mathrm{V}\left(\mathrm{X}_{\mathrm{t}}, \mathrm{Y}_{\mathrm{t}}\right), \mathrm{V}\left(\mathrm{X}_{\mathrm{t}}, \mathcal{I}\right)-\left(\mathcal{I}-\mathrm{Y}_{\mathrm{t}}\right)\right]
$$

units of money. Consequently, when

$$
\mathrm{V}\left(\mathrm{X}_{\mathrm{t}}, \mathcal{I}\right)-\mathrm{V}\left(\mathrm{X}_{\mathrm{t}}, \mathrm{Y}_{\mathrm{t}}\right)>\left(\mathcal{I}-\mathrm{Y}_{\mathrm{t}}\right) \text {, }
$$

by choosing to raise cash by way of shareholders' buyout, the shareholders actually increase the value of the equity that they own by $f_{2} \times 100 \%$, where

$$
F_{2}=\frac{\mathrm{V}\left(\mathrm{X}_{\mathrm{t}}, \mathcal{I}\right)-\mathrm{V}\left(\mathrm{X}_{\mathrm{t}}, \mathrm{Y}_{\mathrm{t}}\right)-\left(\mathcal{I}-\mathrm{Y}_{\mathrm{t}}\right)}{\mathrm{V}\left(\mathrm{X}_{\mathrm{t}}, \mathrm{Y}_{\mathrm{t}}\right)} .
$$

It is interesting that the last quantity is greater than $f_{0}$ when the transaction fee rate $\vartheta$ is positive and one has $f_{2}=f_{0}$ only when $\vartheta=0$. Consequently, public trading and shareholders buyout are equally beneficial for the acting shareholders only when public trading involves no transaction costs. Notice that, if $\mathrm{Y}_{\mathrm{t}}<\mathcal{I}$ and, at the same time, (4.4) holds, the one has

$$
\frac{\mathrm{V}\left(\mathrm{X}_{\mathrm{t}}, I\right)-\mathrm{V}\left(\mathrm{X}_{\mathrm{t}}, \mathrm{Y}_{\mathrm{t}}\right)-\left(I-\mathrm{Y}_{\mathrm{t}}\right)}{\mathrm{V}\left(\mathrm{X}_{\mathrm{t}}, \mathrm{Y}_{\mathrm{t}}\right)}>\frac{\mathrm{V}\left(\mathrm{X}_{\mathrm{t}}, I\right)-\mathrm{V}\left(\mathrm{X}_{\mathrm{t}}, \mathrm{Y}_{\mathrm{t}}\right)-\left(I-\mathrm{Y}_{\mathrm{t}}\right)}{\mathrm{V}\left(\mathrm{X}_{\mathrm{t}}, \mathrm{Y}_{\mathrm{t}}\right)+I-\mathrm{Y}_{\mathrm{t}}},
$$

which means that the shareholders are better off using shareholders' buyout, or, if available, public trading without transaction costs, rather than internal trading.

Finally, we will consider the shareholders' buyout from the point of view of the shareholders' combined wealth, which we suppose includes equity in the firm plus cash in a private bank account. For the sake of simplicity we will suppose that there is only one shareholder who owns $100 \%$ equity in the firm and has $\mathrm{z} \geqslant 0$ units of money in her private bank account. Assuming that $Y_{t}<\mathcal{I}$, if condition (4.4) holds, the owner can instantly increase her combined wealth from something worth $\mathrm{z}+\mathrm{V}\left(\mathrm{X}_{\mathrm{t}}, \mathrm{Y}_{\mathrm{t}}\right)$ units of money to something worth

$$
\mathrm{V}\left(\mathrm{X}_{\mathrm{t}}, \mathcal{I}\right)+\mathrm{z}-\left(\mathcal{I}-\mathrm{Y}_{\mathrm{t}}\right)
$$

units of money by either selling the firm for its market value of $\mathrm{V}\left(\mathrm{X}_{\mathrm{t}}, \mathcal{I}\right)-\left(\mathcal{I}-\mathrm{Y}_{\mathrm{t}}\right)$ units of money, or by taking $\mathcal{I}-\mathrm{Y}_{\mathrm{t}}$ units of money from her private bank and investing this amount in the firm. In either case, the transaction leads to an increase in the owner's combined wealth by

$$
\frac{\mathrm{V}\left(\mathrm{X}_{\mathrm{t}}, \mathcal{I}\right)-\mathrm{V}\left(\mathrm{X}_{\mathrm{t}}, \mathrm{Y}_{\mathrm{t}}\right)-\left(\mathcal{I}-\mathrm{Y}_{\mathrm{t}}\right)}{\mathrm{V}\left(\mathrm{X}_{\mathrm{t}}, \mathrm{Y}_{\mathrm{t}}\right)+\mathrm{Z}} \times 100 \%
$$

Notice that the rate of increase is the largest when $\mathrm{z}=0$. But should the owner take money out of the firm in the form of dividends, say? As was explained in the previous section, when $\mathrm{Y}_{\mathrm{t}} \leqslant \mathcal{I}$, taking cash out of the firm can only decrease the owner's com: bined wealth and this is true regardless of whether the firm is exempt from taxes or not. It is important to remember that this and all other calculations presented in this 
section completely ignore the owner's consumption preferences and the owner's level of risk tolerance.

\section{§5. The Price of a Liquid Firm with an Option to Expand}

Since we have shown that shareholders' buyout benefits shareholders in the same way that public trading without transaction costs does, we will describe only the pricing method for a liquid firm with an option to expand when the available form of equity financing is either public trading (with or without transaction costs), or internal trad: ing, which we suppose is cost-free. Let $(\mathrm{x}, \mathrm{y}) \longrightarrow \mathrm{V}(\mathrm{x}, \mathrm{y})$ be the valuation map associ: ated with an illiquid firm with an option to expand which was calculated in $\S 3$ with $\theta=0$ and with $\theta=0.3$ - recall that $\theta$ is the tax rate applied to any cash paid out to the shareholders. In order to compute the valuation map $(\mathrm{x}, \mathrm{y}) \longrightarrow \mathcal{V}(\mathrm{x}, \mathrm{y})$ for a liquid firm with an option to expand which has access to equity financing in terms of public trading, we must repeat the backward induction procedure described in $\S 3$, after replacing (3.10) with the following recursive rûle for $\mathrm{j}=\mathrm{n}, \ldots, 1$ :

$$
\begin{array}{r}
\mathrm{V}_{\mathrm{i}, \mathrm{j}-1}=e^{-\mathrm{r} \tau_{\mathrm{j}}} \mathrm{E}\left[\operatorname{Max}\left[\mathrm{f}_{\mathrm{j}}\left(\mathrm{x}_{\mathrm{i}} e^{\sigma{\beta_{\mathrm{rj}}}_{\mathrm{j}}+\left(\mathrm{r}-\delta-\frac{1}{2} \sigma^{2}\right) \tau_{\mathrm{j}}}\right), \mathrm{V}\left(\mathrm{x}_{\mathrm{j}}, \mathcal{I}\right)-(1+\vartheta)\left(\mathcal{I}-\mathrm{y}_{\mathrm{j}-1}\right) \times(1+\vartheta)\right]\right], \\
\text { where } \tau_{\mathrm{j}}:=\frac{\mathrm{y}_{\mathrm{j}}-\mathrm{y}_{\mathrm{j}-1}}{\pi\left(\mathrm{x}_{\mathrm{i}}\right)+\mathrm{ry}_{\mathrm{j}-1}}, 1 \leqslant \mathrm{i} \leqslant \mathrm{m},
\end{array}
$$

and $f_{j}(\cdot)$ is computed by way of polynomial interpolation from the assignment $x_{i} \longrightarrow$ $\mathrm{v}_{\mathrm{i}, \mathrm{j}} \cdot \mathrm{J}$ ust as before, the initial data is given by

$$
\mathrm{v}_{\mathrm{i}, \mathrm{n}}=\mathcal{I}+\mathrm{q}_{\theta}\left(\mathrm{x}_{\mathrm{i}}\right)+\mathrm{g}_{\theta}\left(\mathrm{x}_{\mathrm{i}}\right), \text { for } \mathrm{i}=1, \ldots, \mathrm{n},
$$

(notice that this implies that $\mathcal{V}(\mathrm{x}, \mathcal{I})=\mathrm{V}(\mathrm{x}, \mathcal{I})$ for $\mathrm{x} \geqslant 0$ - this is simply saying that when the retained earnings reach the level $\mathcal{I}$ the firm becomes automatically illiquid, since there is no need to raise any additional cash). Once the values $v_{i, j}$ have been computed from the above procedure, the valuation map $\mathcal{V}(\cdot, \cdot)$ can be approximated by way of polynomial interpolation from the assignment $\left(\mathrm{x}_{\mathrm{i}}, \mathrm{y}_{\mathrm{j}}\right) \rightarrow \mathrm{v}_{\mathrm{i}, \mathrm{j}}$. We will use this procedure either with $\vartheta=0$, i.e., without transaction costs, or with $\vartheta=0.1$, i.e., with transaction costs at $10 \%$ rate. Although transaction costs of $10 \%$ are unrealisti: cally high, we have chosen this value in order to amplify - and, consequently, make more visible in our illustrations - the effect that transaction costs have on the share values. All other parameters, including the grid points $\left(x_{i}, y_{j}\right), 0 \leqslant i \leqslant m, 0 \leqslant j \leqslant n$, will have the same values as in $\S 3$ - recall that we are using different sets of grid points for the tax-free case $\theta=0$ and for the case $\theta=0.3$.

The computation of the valuation map ( $\mathrm{x}, \mathrm{y}) \longrightarrow \mathcal{V}(\mathrm{x}, \mathrm{y})$ for a liquid firm that has access to equity financing in terms of internal trading is completely analogous: in this case, (3.10) must be replaced by (recall that we do not consider transaction costs in the case of internal trading)

$$
\begin{array}{r}
\mathrm{V}_{\mathrm{i}, \mathrm{j}-1}=e^{-\mathrm{r} \tau_{\mathrm{j}}} \mathrm{E}\left[\operatorname{Max}\left[\mathrm{f}_{\mathrm{j}}\left(\mathrm{x}_{\mathrm{i}} e^{\sigma \beta_{\tau}+\left(\mathrm{r}-\delta-\frac{1}{2} \sigma^{2}\right) \tau_{\mathrm{j}}}\right), \frac{\mathrm{V}\left(\mathrm{x}_{\mathrm{i}}, \mathrm{y}_{\mathrm{j}-1}\right) \times \mathrm{V}\left(\mathrm{x}_{\mathrm{i}}, \mathcal{I}\right)}{\mathrm{V}\left(\mathrm{x}_{\mathrm{i}}, \mathrm{y}_{\mathrm{j}-1}\right)+\mathcal{I}-\mathrm{y}_{\mathrm{j}-1}}\right]\right], \\
\text { where } \tau_{\mathrm{j}}:=\frac{\mathrm{y}_{\mathrm{j}}-\mathrm{y}_{\mathrm{j}-1}}{\pi\left(\mathrm{x}_{\mathrm{i}}\right)+\mathrm{ry}_{\mathrm{j}-1}}, 1 \leqslant \mathrm{i} \leqslant \mathrm{m},
\end{array}
$$

and $\mathrm{f}_{\mathrm{j}}(\cdot)$ and $\mathrm{v}_{, \mathrm{n}}$ are defined as above.

First, we will give the results for a publicly traded firm without taxes and transaction costs. 


$$
\text { (g10.jpg) }
$$

Fig. 10: The MRSRE for a publicly traded firm with an option to expand when $\theta=0$ and $\theta=0$.

The last plot shows that without taxes and transaction costs, the MRSRE for a publicly traded firm is identically equal to 1 in the entire state-space - this is nothing but a re-statement of the classical Modigliani-Miller proposition. In particular, for $\mathrm{x} \geqslant 0$ and for $0 \leqslant \mathrm{y} \leqslant I$ one has

$$
\mathcal{V}(\mathrm{x}, \mathrm{y})=\mathcal{V}(\mathrm{x}, \mathcal{I})-\int_{\mathrm{y}}^{I} \mathcal{V}^{(0,1)}(\mathrm{x}, \mathrm{z}) d \mathrm{z}=\mathrm{V}(\mathrm{x}, \mathcal{I})-(\mathcal{I}-\mathrm{y}) \equiv \mathrm{y}+\mathrm{q}(\mathrm{x})+\mathrm{g}(\mathrm{x}) .
$$

Since for every choice of $\mathrm{x} \geqslant 0$ and $0 \leqslant \mathrm{y}<\mathcal{I}$ the value of the liquid firm $\mathcal{V}(\mathrm{x}, \mathrm{y})$ coin: cides with the value of the equity that the acting shareholders own after rasing $\mathcal{I}-\mathrm{y}$ units of money by way of public trading, it follows that in any state $\left(\mathrm{X}_{\mathrm{t}}, \mathrm{Y}_{\mathrm{t}}\right)$ the optimal decision is to issue and sell immediately equity worth $I-Y_{t}$ units of money. It is interesting that this decision is optimal even when exercising the investment opportu: nity is not, i.e., even when $\mathrm{X}_{\mathrm{t}}<\mathrm{x}^{*}$.

Next, we give the numerical results for a publicly traded firm that is not sub: ject to taxes but equity trading is subject to $10 \%$ transaction cost.

$$
\text { (g11.jpg) }
$$

Fig. 11: The value of a publicly traded firm with an option to expand when $\theta=0$ and $\vartheta=0.1$.

$$
\text { (g12.jpg) }
$$

Fig. 12: The MRSRE for a publicly traded firm with an option to expand when $\theta=0$ and $\vartheta=0.1$.

$$
\text { (g13.jpg) }
$$

Fig. 13: The MRSRE for a publicly traded firm with an option to expand when $\theta=0$ and $\vartheta=0.1$.

$$
\text { (g14.jpg) }
$$

Fig. 14: The optimal equity trading rûle for a publicly traded firm with an option to expand when $\theta=0$ and $\theta=0.1$ - the region where selling equity is optimal is shown in red.

As the last two plots show, in the region where equity trading is optimal one has $\mu=1+\vartheta$, which is easy to explain: if raising $\varepsilon$ units of money costs $\vartheta \varepsilon$ units of money, removing $\varepsilon$ units of money from the firm decreases its value by $(1+\vartheta) \varepsilon$ units of money. In addition, the last plot shows that for lower levels of retained earnings the critical threshold for the output price that triggers expansion is larger than $\mathrm{x}^{*}$ - this is because, in effect, the transaction costs increases the investment cost.

Next, we present the numerical results for an internally traded firm which is exempt from taxes - recall that we do not consider transaction costs in the case of internal trading.

$$
\text { (g15.jpg) }
$$

Fig. 15: The value of an internally traded firm with an option to expand when $\theta=0$. 


$$
\text { (g16.jpg) }
$$

Fig. 16: The MRSRE for an internally traded firm with an option to expand when $\theta=0$.

$$
\text { (g17.jpg) }
$$

Fig. 17: The MRSRE for an internally traded firm with an option to expand when $\theta=0$.

$$
\text { (g18.jpg) }
$$

Fig. 18: The optimal equity trading rûle for an internally traded firm with an option to expand when $\theta=0$-the region where selling equity is optimal is shown in red.

Finally, we will present the numerical results for a liquid firm - either pub: licly, or internally traded - which is subject to $30 \%$ corporate tax. Recall that when all cash taken out of the firm is subject to $30 \%$ tax, the critical threshold for the output price that triggers new investment is $\mathrm{x}^{*} \approx 5.80917$.

$$
\text { (g19.jpg) }
$$

Fig. 19: The value of a publicly traded firm with an option to expand when $\theta=0.3$ and $\vartheta=0$

$$
\text { (g20.jpg) }
$$

Fig. 20: The MRSRE for a publicly traded firm with an option to expand when $\theta=0.3$ and $\vartheta=0$.

$$
\text { ( } 2 \text { 21.jpg) }
$$

Fig. 21: The MRSRE for a publicly traded firm with an option to expand when $\theta=0.3$ and $\theta=0$

$$
\text { (g22.jpg) }
$$

Fig. 22: The optimal equity trading rûle for a publicly traded firm with an option to expand when $\theta=0.3$ and $\vartheta=0$ - the region where selling equity is optimal is shown in red.

$$
\text { (g23.jpg) }
$$

Fig. 23: The value of a publicly traded firm with an option to expand when $\theta=0.3$ and $\vartheta=0.1$

$$
\text { (g24.jpg) }
$$

Fig. 24: The MRSRE for a publicly traded firm with an option to expand when $\theta=0.3$ and $\vartheta=0.1$.

$$
\text { (g25.jpg) }
$$

Fig. 25: The MRSRE for a publicly traded firm with an option to expand when $\theta=0.3$ and $\theta=0.1$

$$
\text { (g26.jpg) }
$$

Fig. 26: The optimal equity trading rûle for a publicly traded firm with an option to expand when $\theta=0.3$ and $\theta=0.1$ - the region where selling equity is optimal is shown in red. 


$$
\text { (g27.jpg) }
$$

Fig. 27: The value of a publicly traded firm with an option to expand when $\theta=0.3$.

$$
\text { (g28.jpg) }
$$

Fig. 28: The MRSRE for an internally traded firm with an option to expand when $\theta=0.3$.

$$
\text { (g29.jpg) }
$$

Fig. 29: The MRSRE for an internally traded firm with an option to expand when $\theta=0.3$.

$$
\text { (g30.jpg) }
$$

Fig. 30: The optimal equity trading rûle for an internally traded firm with an option to expand when $\theta=0.3$ - the region where selling equity is optimal is shown in red.

\section{§6. Conclusions}

Without any doubt, the model discussed in the present paper is a vast oversimplifica: tion of the real financial phenomena that it tries to explain. Indeed, in practice, invest: ment opportunities are not well defined and in most cases involve many levels of uncertainty. Furthermore, most firms do use leverage as a financial tool and in most cases have some flexibility in choosing the size of the expansion projects. Nevertheless, our study of the pricing equation (3.1) revealed features that are certainly universal. For example, it is clear from the results presented in $\S 3$ and $\S 5$ that, unless one of the following two assumptions can be made:

1) the firm has no opportunity to expand;

2) the firm is exempt from taxes and can auction equity at no cost with a very large number of competing buyers;

in general, one cannot expect the share value to be a linear function of the amount of cash owned by the firm and, consequently, from the owners' point of view, the value of an amount of money kept in the firm may be different from the value of the same amount kept in a bank outside the firm. Furthermore, it is clear from the argument presented in $\S 4$ that this last feature is actually needed in order to explain why firms do sell equity even when selling equity costs money. More importantly, our analysis showed that, on principle, it is possible to quantify the shareholders' preference for having money in the firm, rather than in a bank accounts, in a way that takes into account the firm's opportunity to expand.

Of course, many extensions and modifications of the model discussed in the present paper are possible. Some of them are simply a matter of a technicality - for example, it is easy to adapt the procedure discussed in $\S 3$ and $\S 5$ to the case where the transaction costs are shared by both buyers and sellers, or to the case where the tax policy is somehow different. Other extensions may require only a minor increase in the computational complexity of the procedure that we used - for example, at each step the procedure may optimize the amount of cash that the firm raises by selling equity, instead of assuming that this amount can only equal to $\mathcal{I}-\mathrm{Y}_{\mathrm{t}}$. At the same time, other generalizations may require a substantial increase in the computational complexity of the procedure - for example, the backward induction procedure used in §5 may incor: porate shareholders' consumption preferences and/or risk aversion. Also, the same 
procedure may incorporate the choice of scale in the expansion project. In addition, by increasing the number of variables one may incorporate in the model certain types of uncertainty in the investment opportunity that the firm has. The fact that we have not been able to provide a closed form solution to the pricing equation even with the over: simplifying assumptions that we used is certainly a drawback. Nevertheless, the results presented in $\S 3$ and $\S 5$ show that, on principle, the recent advances in computing technology can reduce the significance of such drawbacks and can expand the crux of tractable financial models.

\section{Appendix}

\section{Derivation of the Fundamental Pricing Equation (3.1)}

\section{Method I: computing the price of risk}

Recall that the convenience yield from holding items produced by the firm is $\delta>0$ and that the expected growth rate in the price of those items is $\alpha=\varrho-\delta$. Thus, from equa: tion (1.1), the instantaneous gain from investing the amount $\mathrm{X}_{\mathrm{t}}$ in one unit of the firm's output is

$$
d \mathrm{X}_{\mathrm{t}}+\delta \mathrm{X}_{\mathrm{t}} d \mathrm{t}=\sigma \mathrm{X}_{\mathrm{t}} d \aleph_{\mathrm{t}}+(\alpha+\delta) \mathrm{X}_{\mathrm{t}} d \mathrm{t}
$$

The expected value of this gain, conditioned to information available at time $t>0$, is simply $(\alpha+\delta) \mathrm{X}_{\mathrm{t}} d \mathrm{t} \equiv \varrho \mathrm{X}_{\mathrm{t}} d \mathrm{t}$. If the same amount $\mathrm{X}_{\mathrm{t}}$ is invested at no risk in a money market account, the instantaneous gain would be $\mathrm{rX}_{\mathrm{t}} d \mathrm{t}$. The difference $\varrho \mathrm{X}_{\mathrm{t}} d \mathrm{t}-\mathrm{r} \mathrm{X}_{\mathrm{t}} d \mathrm{t}=(\varrho-\mathrm{r}) \mathrm{X}_{\mathrm{t}} d \mathrm{t}$ is the risk premium for allowing the instantaneous gain from investing in one unit of output to fluctuate around its average by the amount $\sigma \mathrm{X}_{\mathrm{t}} d \aleph_{\mathrm{t}}$. If all arbitrage opportunities are cleared out, the risk premium from any investment that fluctuates around its average by an amount which is a multiple of the amount $\sigma \mathrm{X}_{\mathrm{t}} d \aleph_{\mathrm{t}}$ must equal the same multiple of the amount $(\varrho-\mathrm{r}) \mathrm{X}_{\mathrm{t}} d \mathrm{t}$. This is no different from saying that if Lottery A and Lottery B use the same rules and the same drawing and differ only in that the rewards paid by Lottery B equal two times the rewards paid by Lottery A, then the price of one ticket from Lottery B should be the same as the price of two tickets from Lottery A, for otherwise all speculators would either prefer 1 ticket from Lottery B more than they would prefer 2 tickets from Lot: tery A, or vice verse, which means that one of the lotteries will have no customers. According to the Itô formula, the instantaneous gain from investing the amount $\mathrm{V}\left(\mathrm{X}_{\mathrm{t}}, \mathrm{Y}_{\mathrm{t}}\right)$ in the firm must be

$$
\begin{aligned}
& d \mathrm{~V}\left(\mathrm{X}_{\mathrm{t}}, \mathrm{Y}_{\mathrm{t}}\right)=\sigma \mathrm{X}_{\mathrm{t}} \mathrm{V}^{(1,0)}(\mathrm{x}, \mathrm{y}) d \beta_{\mathrm{t}} \\
&+\left(\alpha \mathrm{X}_{\mathrm{t}} \mathrm{V}^{(1,0)}(\mathrm{x}, \mathrm{y})+\frac{1}{2} \sigma^{2} \mathrm{X}_{\mathrm{t}}^{2} \mathrm{~V}^{(2,0)}(\mathrm{x}, \mathrm{y})\right. \\
&\left.+\left(\pi\left(\mathrm{X}_{\mathrm{t}}\right)+\mathrm{rY}_{\mathrm{t}}\right) \times \mathrm{V}^{(0,1)}(\mathrm{x}, \mathrm{y})\right) d \mathrm{t}
\end{aligned}
$$

This gain fluctuates around its conditional expected average at time t by the amount

$$
\mathrm{V}^{(1,0)}\left(\mathrm{X}_{\mathrm{t}}, \mathrm{Y}_{\mathrm{t}}\right) \times \sigma \mathrm{X}_{\mathrm{t}} d \beta_{\mathrm{t}}
$$

and, consequently, the associate risk premium must equal

$$
\mathrm{V}^{(1,0)}\left(\mathrm{X}_{\mathrm{t}}, \mathrm{Y}_{\mathrm{t}}\right) \times(\varrho-\mathrm{r}) \mathrm{X}_{\mathrm{t}} d \mathrm{t} .
$$

However, the actual premium is 


$$
\begin{aligned}
\left(\alpha \mathrm{X}_{\mathrm{t}} \mathrm{V}^{(1,0)}\left(\mathrm{X}_{\mathrm{t}}, \mathrm{Y}_{\mathrm{t}}\right)\right. & +\frac{1}{2} \sigma^{2} \mathrm{X}_{\mathrm{t}}^{2} \mathrm{~V}^{(2,0)}\left(\mathrm{X}_{\mathrm{t}}, \mathrm{Y}_{\mathrm{t}}\right) \\
& \left.+\left(\pi\left(\mathrm{X}_{\mathrm{t}}\right)+\mathrm{r} \mathrm{Y}_{\mathrm{t}}\right) \times \mathrm{V}^{(0,1)}\left(\mathrm{X}_{\mathrm{t}}, \mathrm{Y}_{\mathrm{t}}\right)-\mathrm{rV}\left(\mathrm{X}_{\mathrm{t}}, \mathrm{Y}_{\mathrm{t}}\right)\right) d \mathrm{t} .
\end{aligned}
$$

Taking into account that $\varrho=\alpha+\delta$ and equating (1) and (2) one gets

$$
\begin{aligned}
(\mathrm{r}-\delta) \mathrm{X}_{\mathrm{t}} \mathrm{V}^{(1,0)}\left(\mathrm{X}_{\mathrm{t}}, \mathrm{Y}_{\mathrm{t}}\right)+\frac{1}{2} \sigma^{2} \mathrm{X}_{\mathrm{t}}^{2} \mathrm{~V}^{(2,0)}\left(\mathrm{X}_{\mathrm{t}}, \mathrm{Y}_{\mathrm{t}}\right) \\
+\left(\pi\left(\mathrm{X}_{\mathrm{t}}\right)+\mathrm{r} \mathrm{Y}_{\mathrm{t}}\right) \times \mathrm{V}^{(0,1)}\left(\mathrm{X}_{\mathrm{t}}, \mathrm{Y}_{\mathrm{t}}\right)=\mathrm{rV}\left(\mathrm{X}_{\mathrm{t}}, \mathrm{Y}_{\mathrm{t}}\right),
\end{aligned}
$$

which is exactly equation (3.1).

\section{Method II: hedging the risk}

Consider an investor who, at time $\mathrm{t}>0$, invests the amount $\mathrm{V}\left(\mathrm{X}_{\mathrm{t}}, \mathrm{Y}_{\mathrm{t}}\right)$ in the firm and - simultaneously - sells short $\mathrm{V}^{(1,0)}\left(\mathrm{X}_{\mathrm{t}}, \mathrm{Y}_{\mathrm{t}}\right)$ units of the firm's output. The instanta: neous gain from this position is (notice that the borrower of units of output must pay a "borrowing fee" equal to the convenience yield from the output)

$$
d \mathrm{~V}\left(\mathrm{X}_{\mathrm{t}}, \mathrm{Y}_{\mathrm{t}}\right)-\mathrm{V}^{(1,0)}\left(\mathrm{X}_{\mathrm{t}}, \mathrm{Y}_{\mathrm{t}}\right) d \mathrm{X}_{\mathrm{t}}-\mathrm{V}^{(1,0)}\left(\mathrm{X}_{\mathrm{t}}, \mathrm{Y}_{\mathrm{t}}\right) \delta \mathrm{X}_{\mathrm{t}} d \mathrm{t}
$$

and since this gain is exactly equal to its expected value at time $t-i . e$. , the gain is completely known at time $\mathrm{t}$ - it must coincide with the instantaneous gain from invest: ing the amount $\mathrm{V}\left(\mathrm{X}_{\mathrm{t}}, \mathrm{Y}_{\mathrm{t}}\right)-\partial_{\mathrm{x}} \mathrm{V}\left(\mathrm{X}_{\mathrm{t}}, \mathrm{Y}_{\mathrm{t}}\right) \mathrm{X}_{\mathrm{t}}$ in units of money, which is

$$
\mathrm{r}\left(\mathrm{V}\left(\mathrm{X}_{\mathrm{t}}, \mathrm{Y}_{\mathrm{t}}\right)-\partial_{\mathrm{x}} \mathrm{V}\left(\mathrm{X}_{\mathrm{t}}, \mathrm{Y}_{\mathrm{t}}\right) \mathrm{X}_{\mathrm{t}}\right) d \mathrm{t}
$$

After expanding (4) according to the Itô formula and identifying the resulting expres: sion with (5), one arrives at the same identity as in (3). Algebraically, this method is equivalent to Method I, but, unlike Method I, it uses the assumption that arbitrarily large quantities of the firm's output can be borrowed at no cost.

\section{References}

[1] F. Black and M. Scholes, The Pricing of Options and Corporate Liabilities (J ournal of Political Economy, 81/ 1973, pp: 637-659)

[2] A. Brav, J. Graham, C. Harvey and R. Michaeley, Payout Policy in the 21st Century (Working Paper, Duke University)

[3] M. Brenan and E. Schwartz, Corporate Income Taxes, Valuation, and the Problem of Optimal Capital Structure (J ournal of Business, 51/ 1978, pp: 103- 114)

[4] A. K. Dixit and R. S. Pindyck, Investment Under Uncertainty (Princeton University Press, 1994)

[5] E. Fama and H. Babiak, Dividend Policy: An Empirical Analysis (J ournal of the American Statistical Association, 63(324)/ 1968, pp: 1132-1161)

[6] H. Fan and S. Sundaresan, Debt Valuation, Renegotiations, and Optimal Dividend Policy (Review of Financial Studies, 13/2000, pp: 1057-1099)

[7] R. S. Goldstein, N. J u and H. E. Leland, An EBIT-based Model of Optimal Capital Structure (J ournal of Business, 47/ 2001, pp: 483-512)

[8] Paolo Guasoni, Optimal Investment with Transaction Costs and without Semimartingales (Annals of Applied Probability, 12/2002, pp: 1227-1246)

[9] Hayne E. Leland, Corporate Debt Value, Bond Covenants, and Optimal Capital Structure (J ournal of Finance, 49/ 1994, pp: 1213-1252)

[10] Hayne E. Leland, Agency Costs, Risk Management and Capital Structure (J ournal of Finance, 53/ 1998, pp: 1213- 1243) 
[11] H. E. Leland and K. Toft, Optimal Capital Structure, Endogenous Bankruptcy, and the Term Structure of Credit Spreads (J ournal of Finance, 51/ 1996, pp: 987- 1019)

[12] J ohn Lintner, Distribution of Incomes of Corporations Among Dividends, Retained Earnings, and Taxes (American Economic Review, 46/ 1956, pp: 97-113)

[13] Andrew Lyasoff, Path Integral Methods for Parabolic Partial Differential Equations with Examples from Computational Finance (Mathematica J ournal, 9: 2/2004, pp: 399-422)

[14] Robert C. Merton, A Rational Theory of Option Pricing (Bell J ournal of Economics and Management Science, 4/ 1973, pp: 141-183)

[15] Robert C. Merton, On the Pricing of Corporate Debt: The Risk Structure of Interest Rates (J ournal of Finance, 29/ 1974, pp: 449-469)

[16] Robert C. Merton, Continuous Time Finance (Blackwell Publishing Ltd, 1992)

[17] F. Modigliani and M. Miller, The Cost of Capital, Corporation Finance, and the Theory of Investment (American Economic Review, 6/ 1958, pp: 261-297)

[18] F. Modigliani and M. Miller, Dividend Policy, Growth and the Valuation of Shares (J ournal of Business, 10/ 1961, pp: 411-433)

[19] Michael Rozeff, Growth, Beta and Agency Costs as Determinants of Dividend Payout Ratios (J ournal of Financial Research, 5/ 1982, pp: 249-259)

Notes:

1 This is a working paper. 


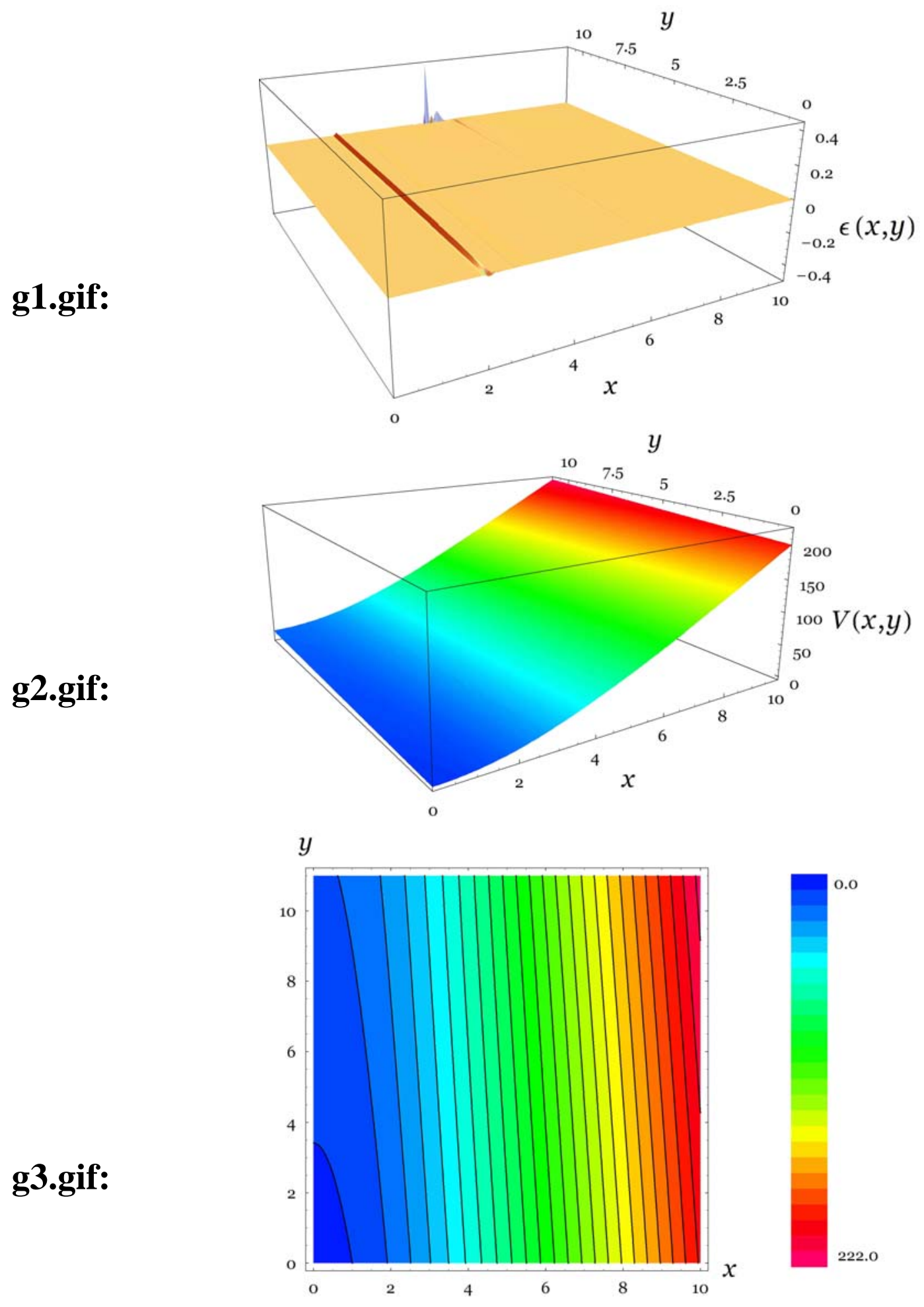


g4.gif:

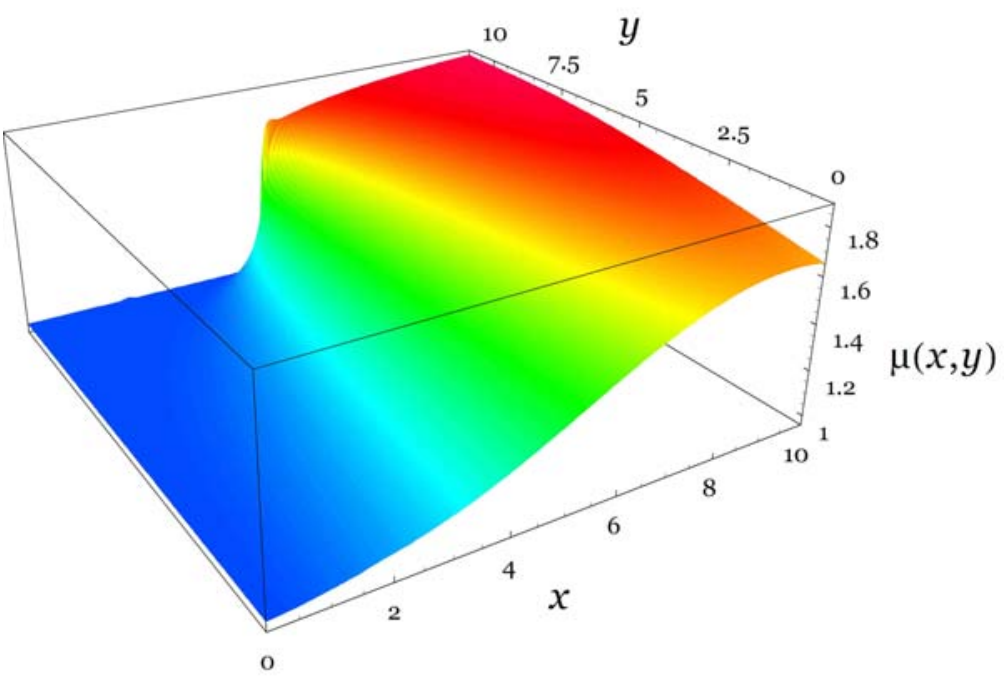

g5.gif:

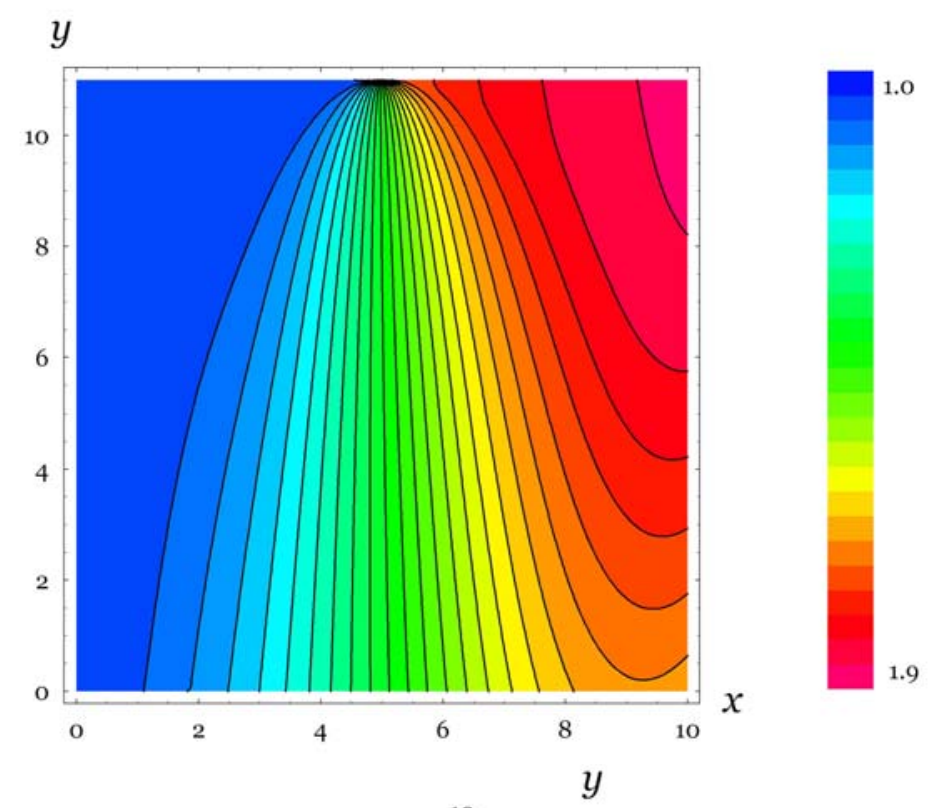

g6.gif:

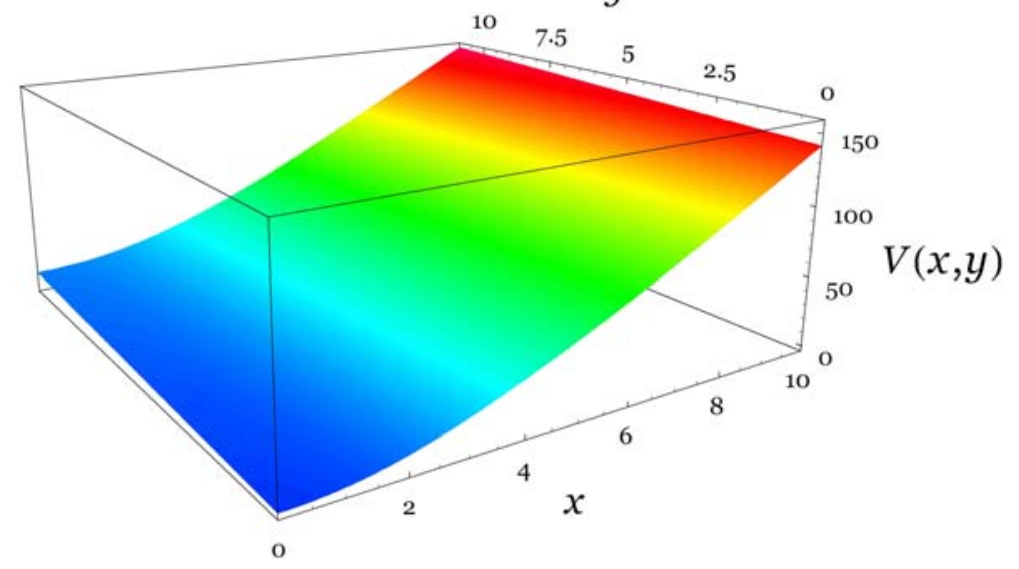



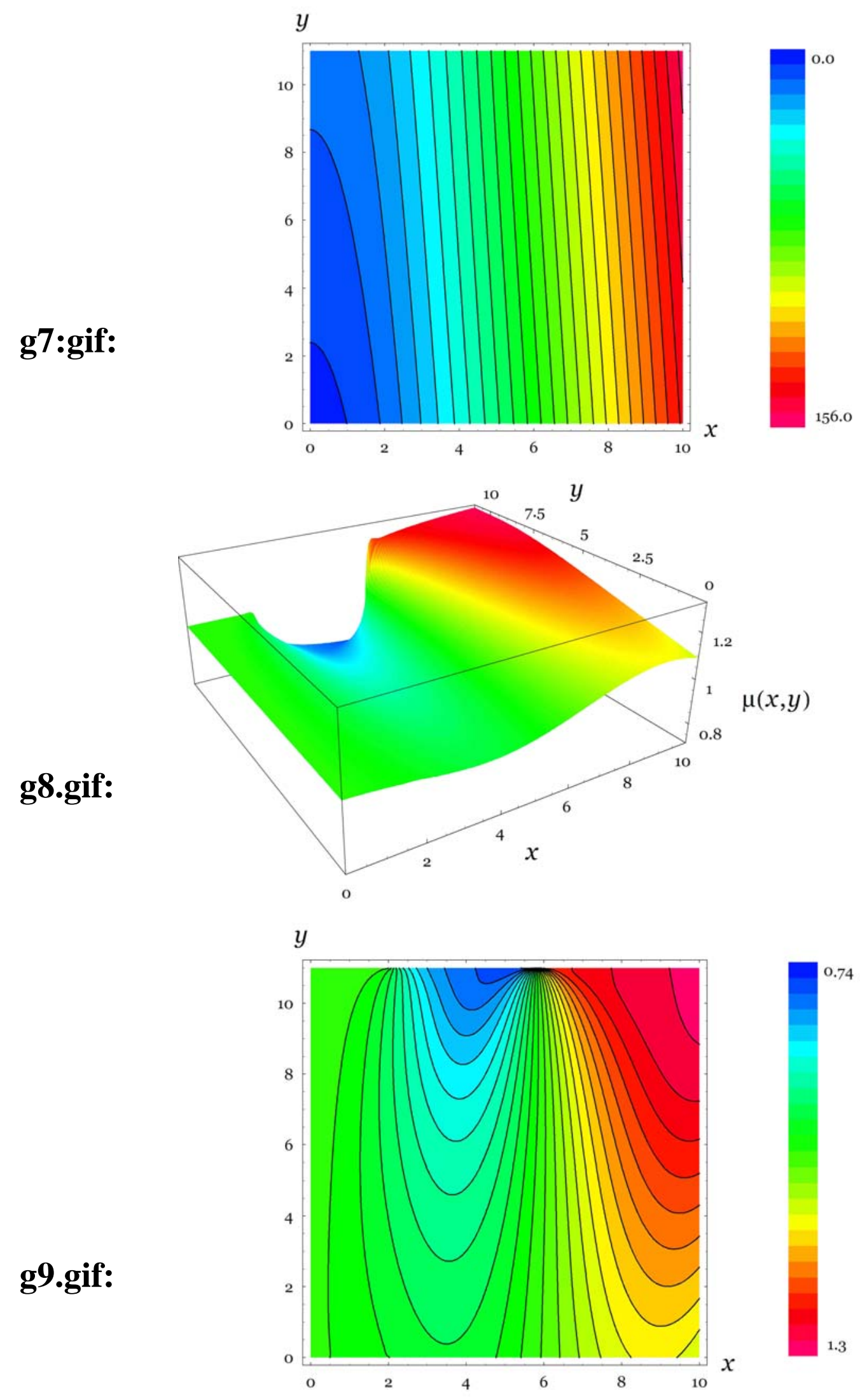

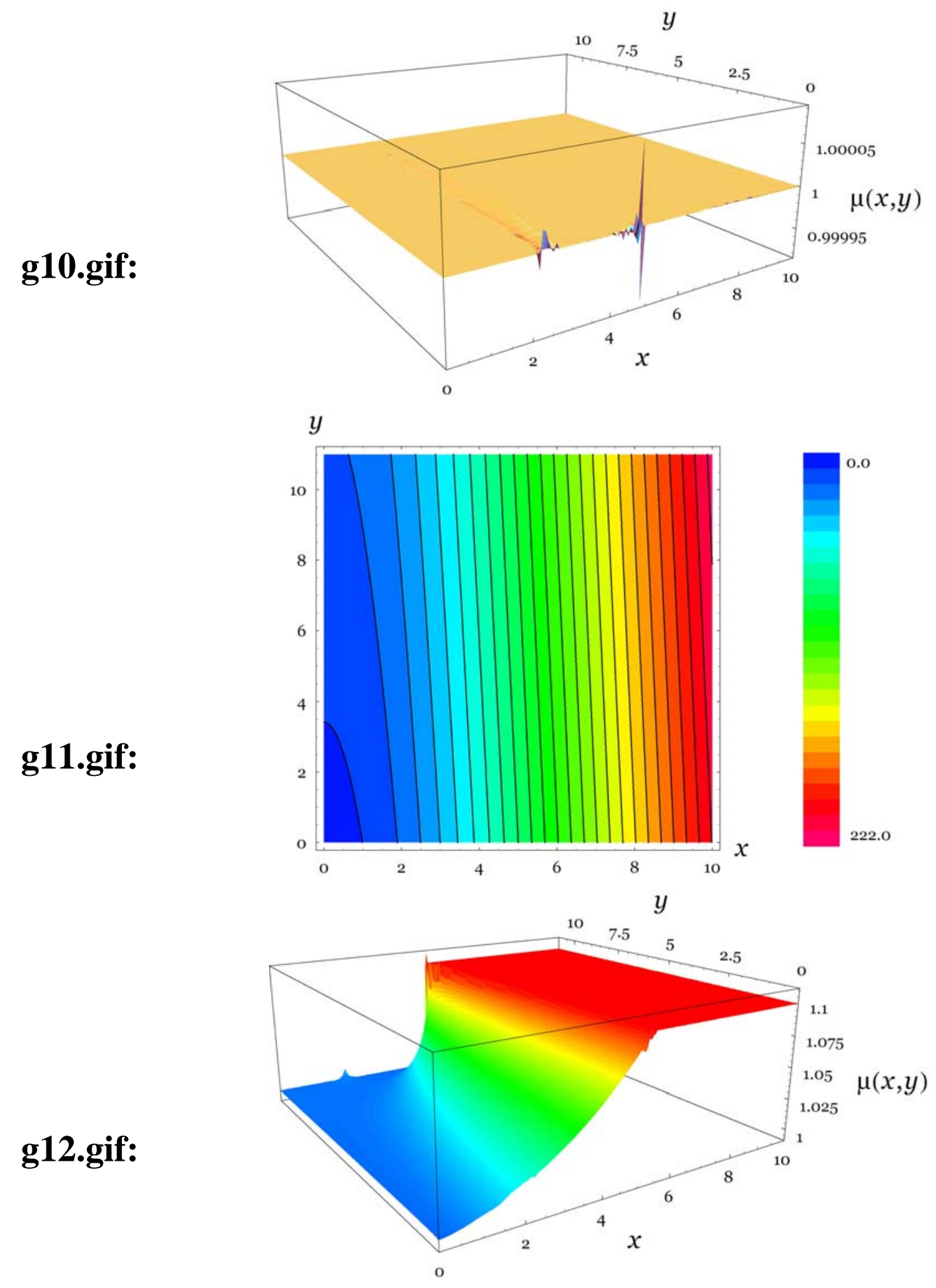


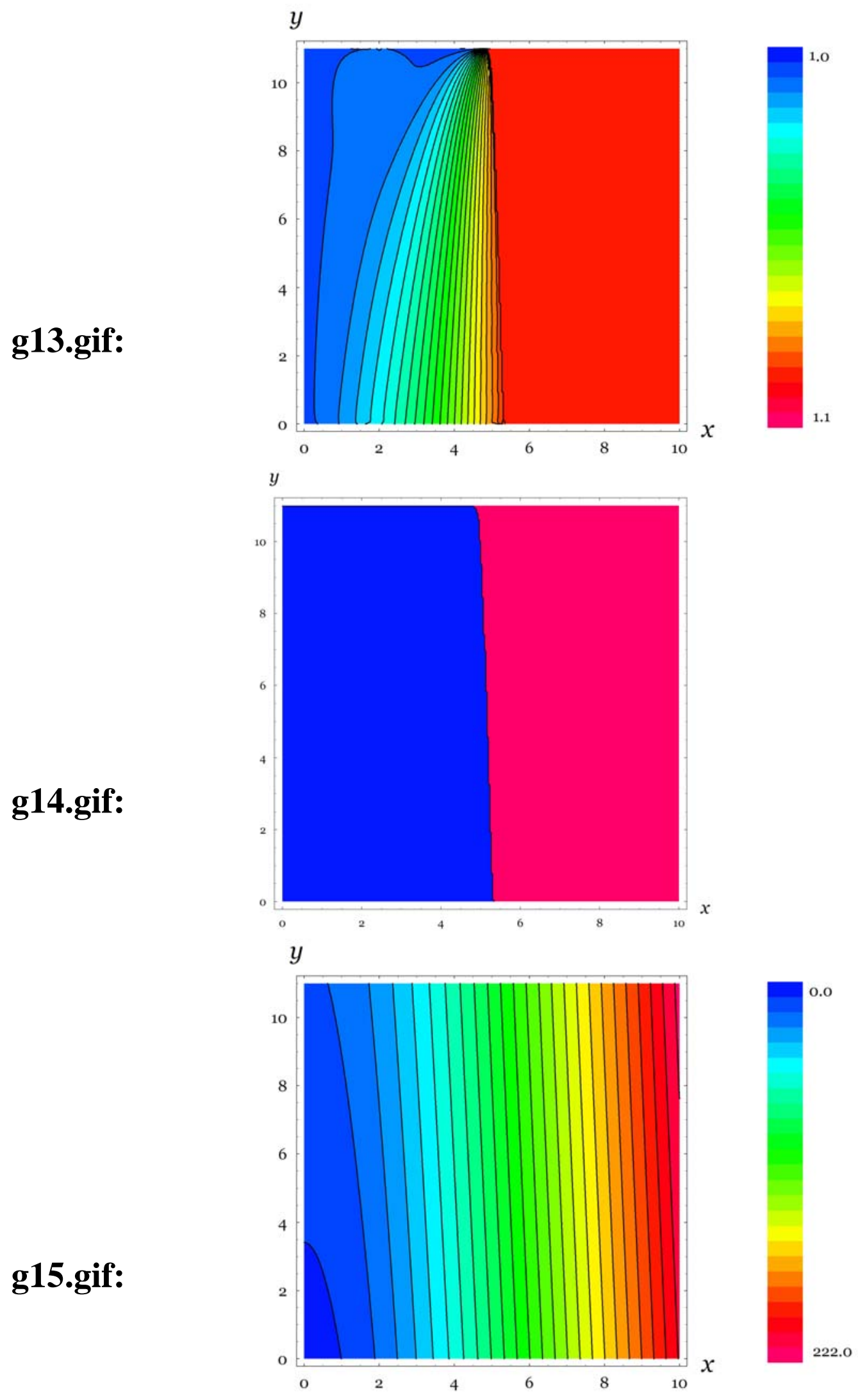


g16.gif:

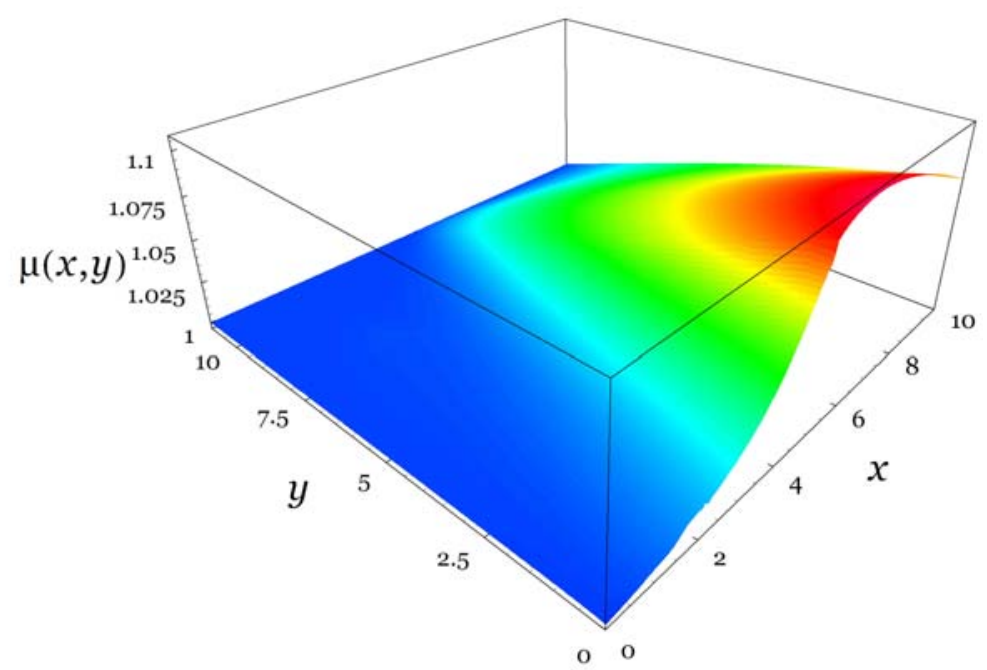

g17.gif:

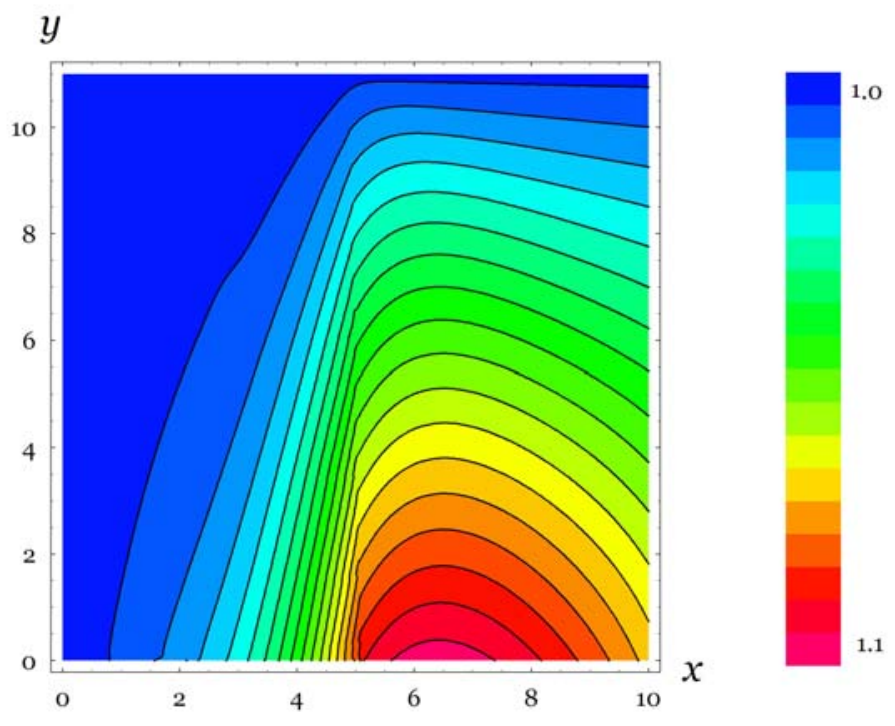

g18.gif:

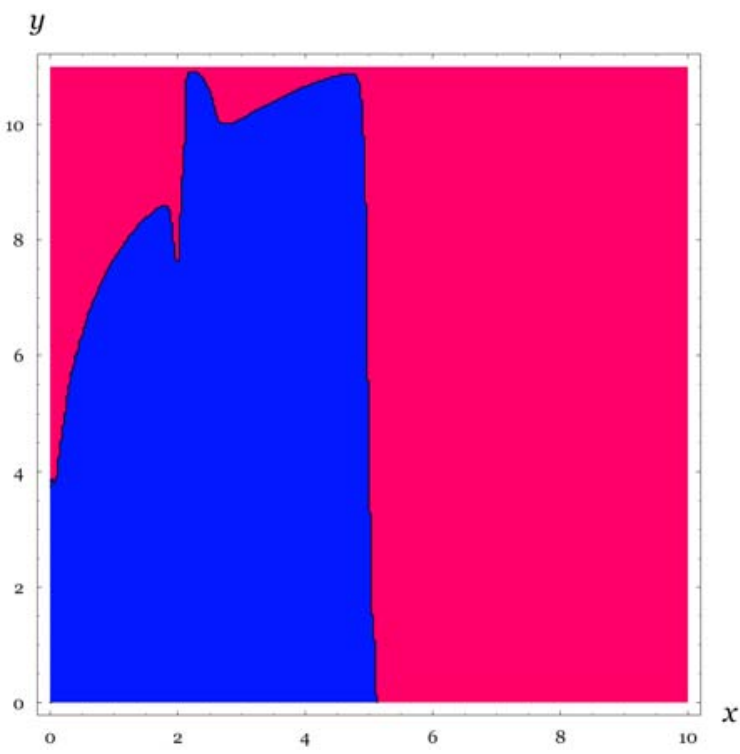




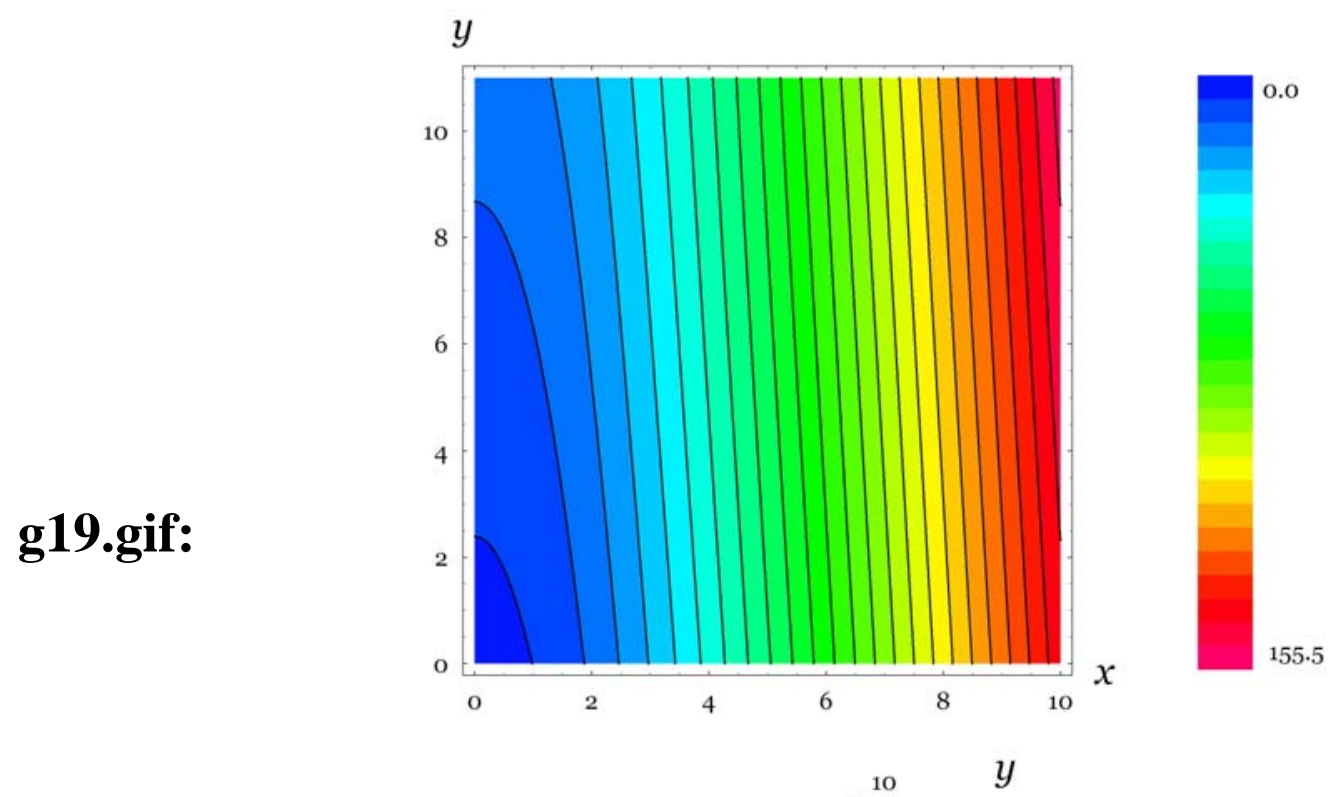

g20.gif:
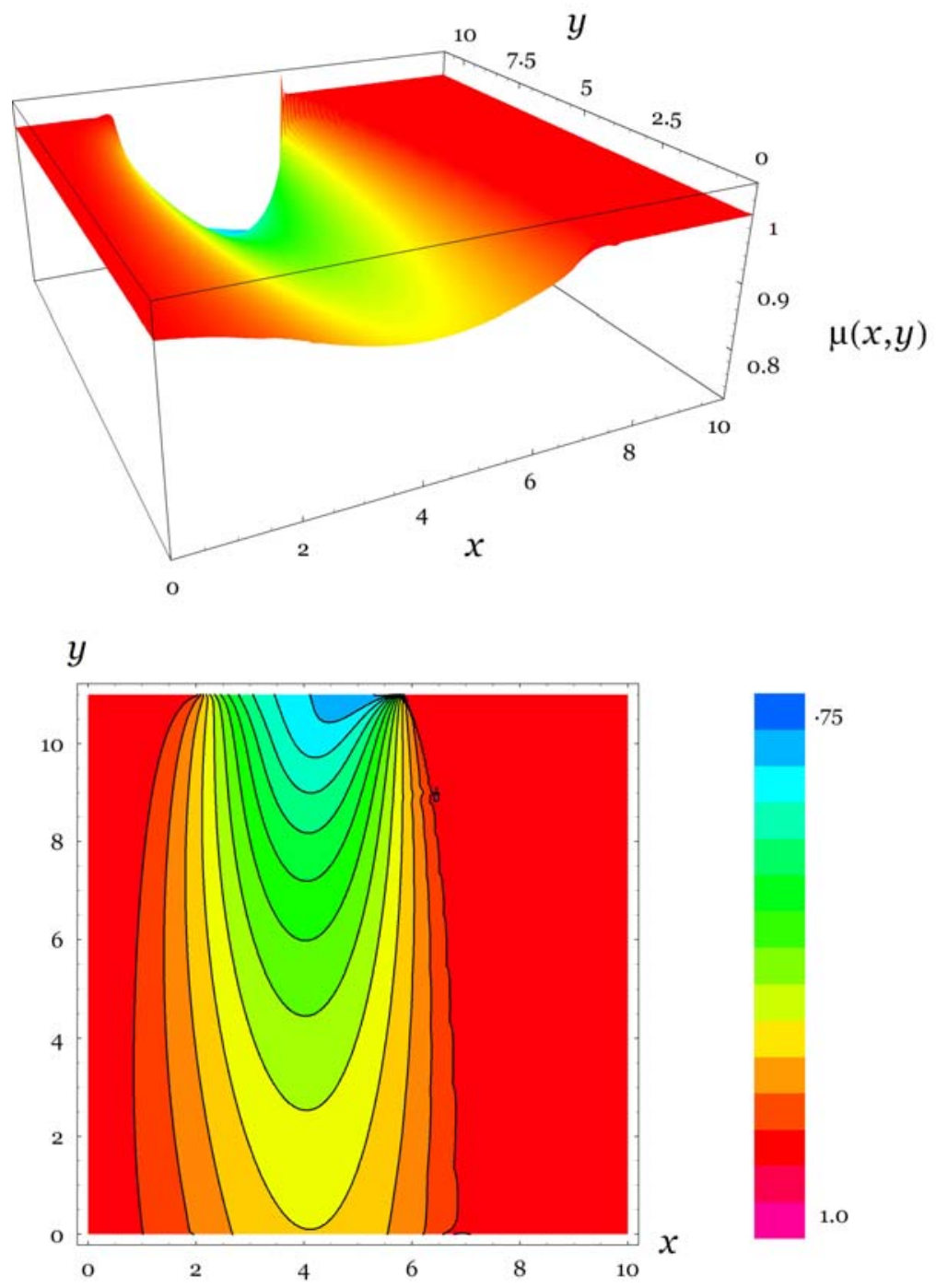

g21.gif: 


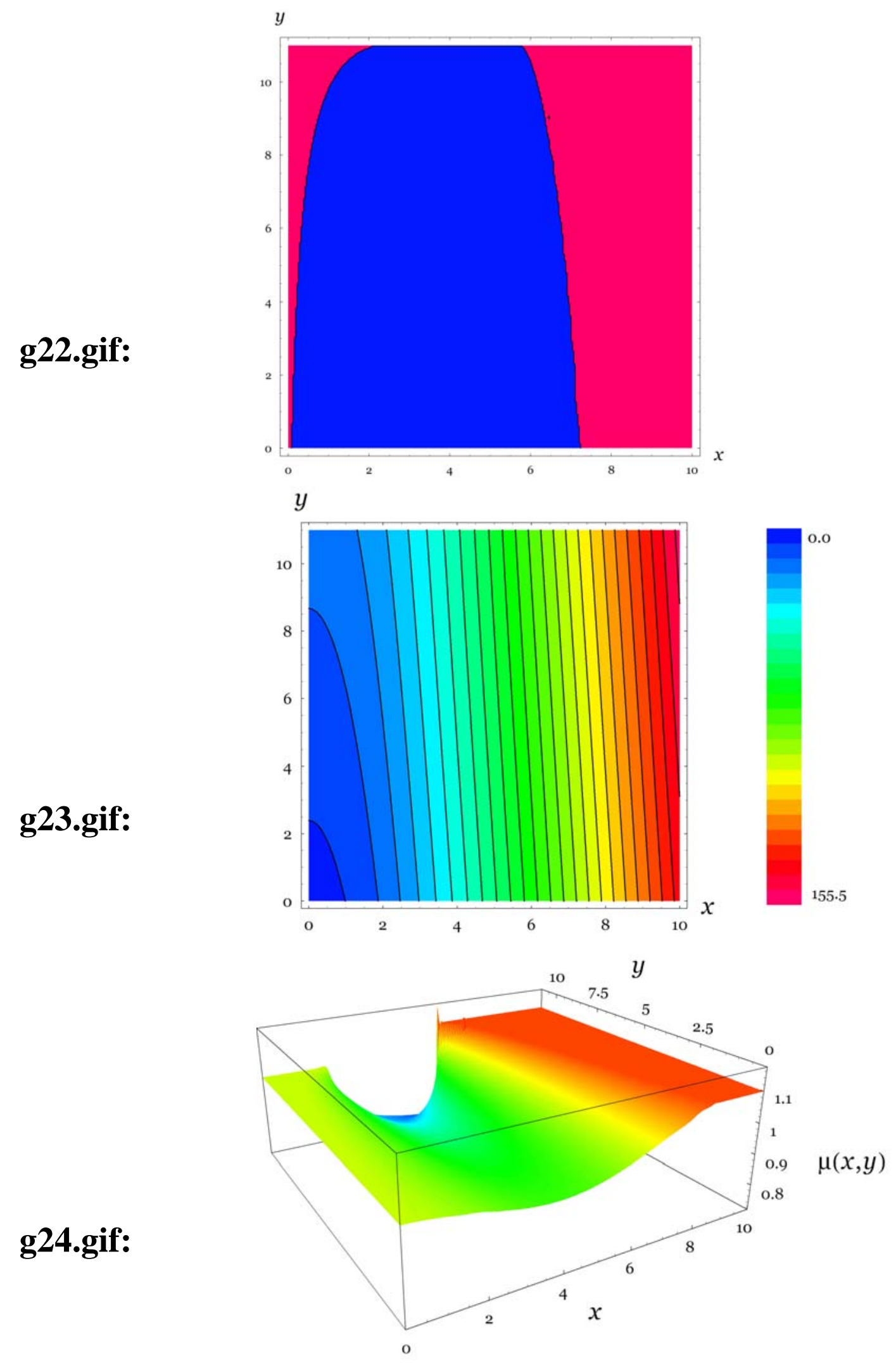


g25.gif:

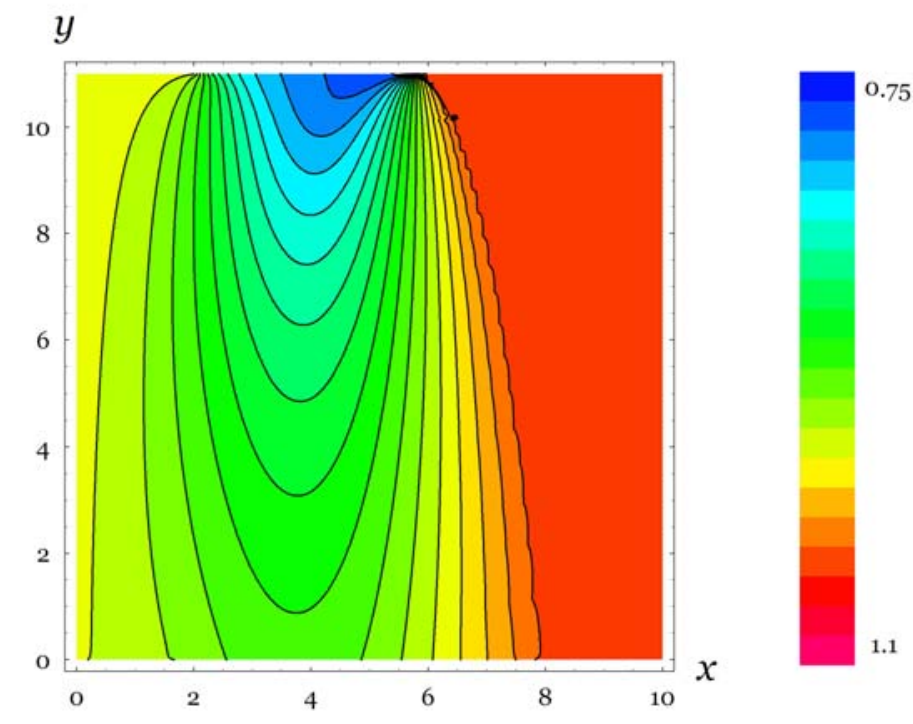

g26.gif:

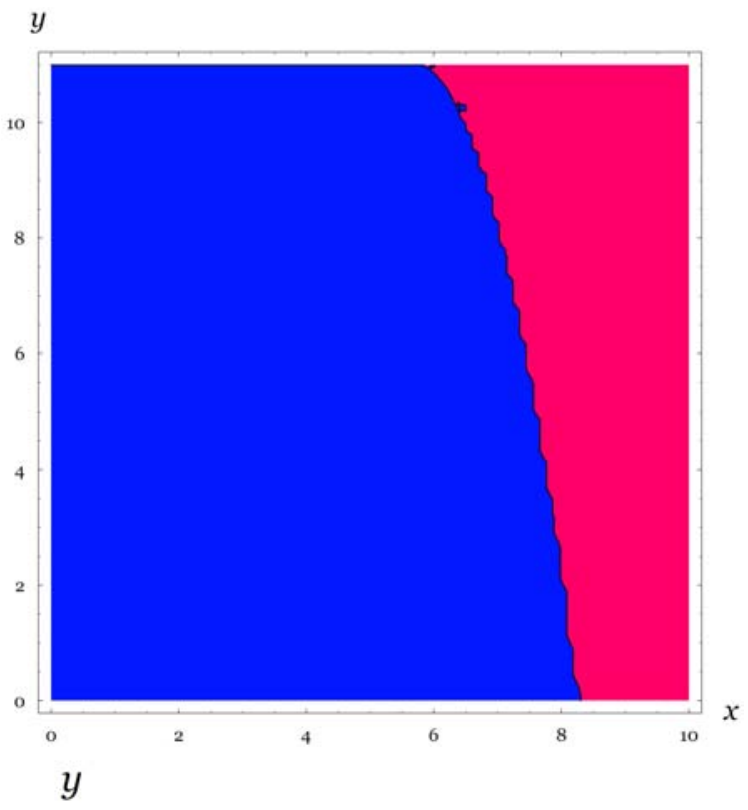

g27.gif:

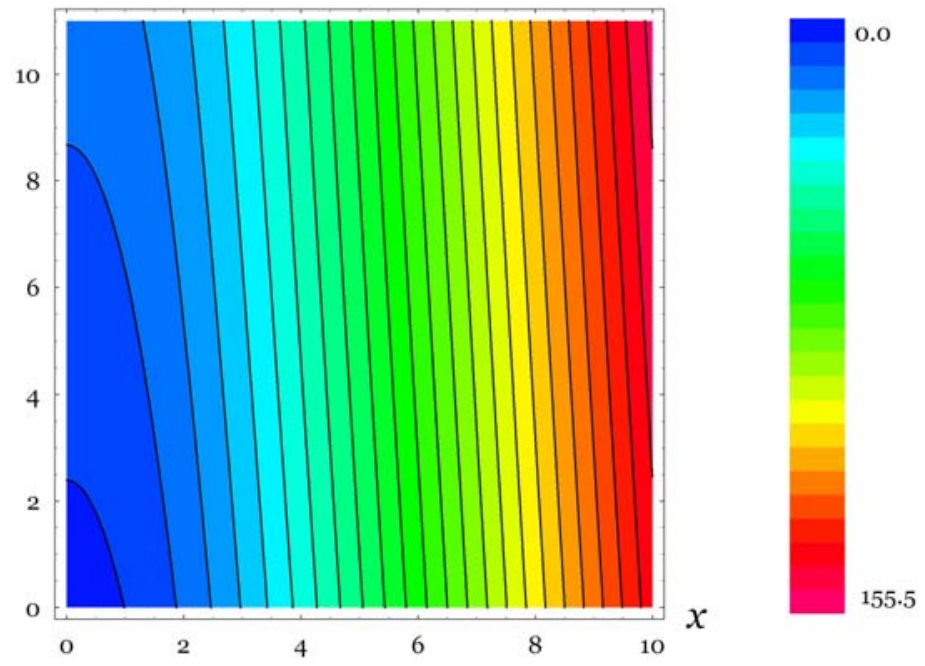




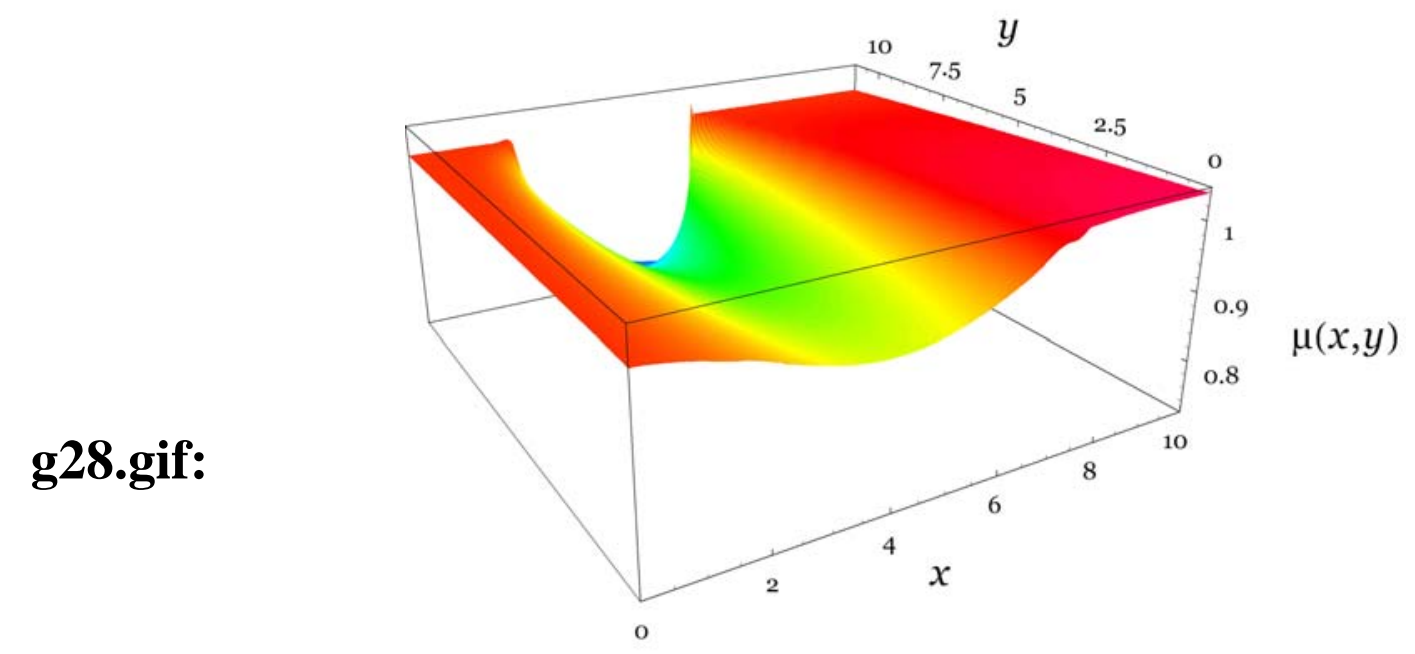

g29.gif:

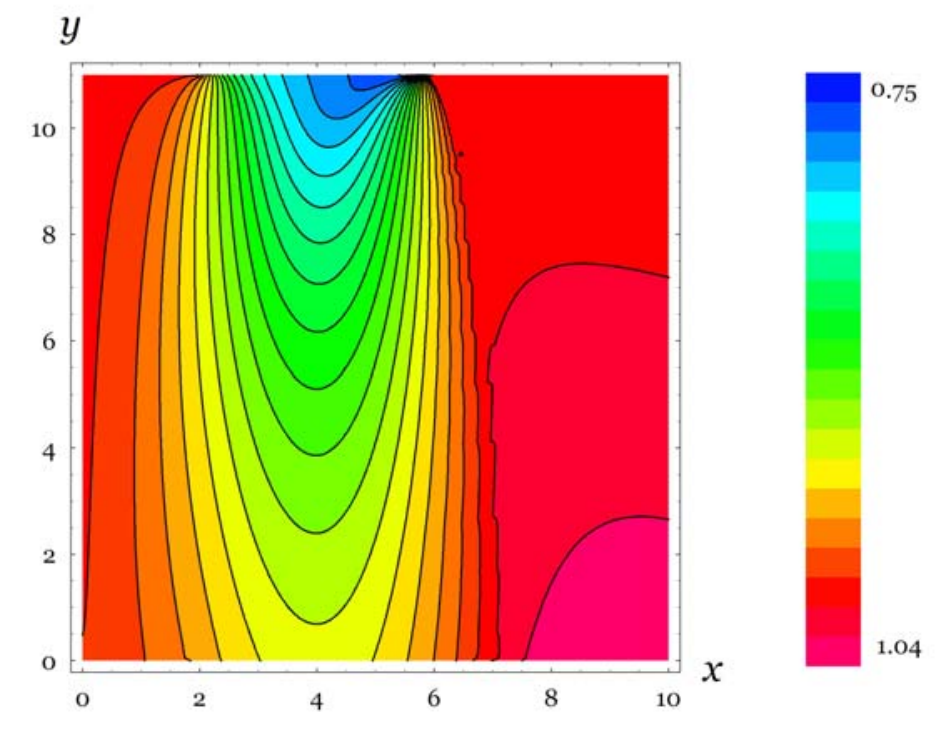

g30.gif:

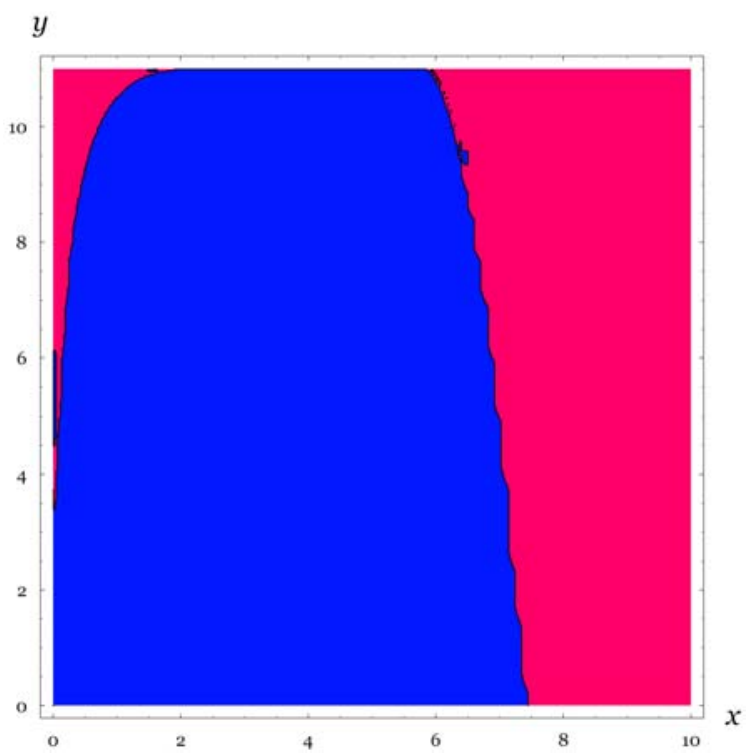

